\title{
Role of Ethylene in the Biosynthetic Pathway of Related-aroma Volatiles Derived from Fatty Acids in Oriental Sweet Melon
}

\author{
Yan $\mathbf{L i}^{1}$ \\ College of Horticultural Science and Engineering, Shangdong Agricultural University, Tai'an \\ 271018, Shandong, People's Republic of China; Scientific Observing and Experimental Station of \\ Environment Controlled Agricultural Engineering in Huang-Huai-Hai Region, Ministry of Agricul- \\ ture, Tai'an 271018, Shandong, People's Republic of China; and State Key Laboratory of Crop \\ Biology, Daizong Street 61, Tai'an 271018, Shandong, People's Republic of China
}

\author{
Hongyan Qi, Yazhong Jin, Xiaobin Tian, Linlin Sui, and Yan Qiu \\ Key Laboratory of Protected Horticulture of Education Ministry and Liaoning Province, College of \\ Horticulture, Shenyang Agricultural University, No.120 Dongling Road, Shenyang, 110866, Liaoning \\ Province, People's Republic of China
}

\begin{abstract}
Additional INDEX words. straight-chain, alcohol, aldehyde, ester, 1-methylcyclopropene, key enzymes
ABstract. The catabolism of fatty acid (FA) is regarded as a key pathway of aroma volatile compounds in oriental sweet melon (Cucumis melo var. makuwa). In our research, two cultivars of oriental sweet melon, Caihong7 and Tianbao, were employed to illuminate which step of the biosynthetic pathway of aroma compounds could be regulated by ethylene (ETH). The role of ETH in determining the profiles of straight-chain aroma volatile compounds, levels of FA as aroma precursors, activities of aroma-related enzymes derived from FA pathway, and expression patterns of key enzymes were investigated. Overall, exogenous application of ETH increased the production rates of endogenous ETH and levels of FA. Compared with control, the level of straight-chain esters, especially the acetate, hexanoate, and hexyl esters, was significantly increased by ETH, whereas the content of alcohol and aldehyde reduced. In addition, the metabolism of free FA included linoleic acid (LA), linolenic acid (LeA), and oleic acid (OA) appeared to be ETHdependent. The activities of lipoxygenase (LOX), alcohol dehydrogenase (ADH), and alcohol acetyltransferase (AAT) as well as the expression patterns of $C m-A D H 1, C m-A D H 2, C m-A A T 1$, and $C m-A A T 4$ were positively regulated by ETH. In contrast, hydroperoxide lyase (HPL) and $C m-A A T 2$ and $C m-A A T 3$ seemed to be independent of ETH modulation. These results suggested that the dissimilation of FA included LA, LeA, and OA into the acetate, hexanoate, and hexyl esters mainly through ETH regulating the LOX pathway by enhancing the expression of particular members of aroma-related key enzyme gene families as well as the activities of dehydrogenation and esterification.
\end{abstract}

Oriental sweet melon presents several attractive qualities, such as a sweet and crisp taste, juicy flesh, edible peel, and especially the intense aroma (Allwood et al., 2014; Aubert and Bourger, 2004; Bai et al., 2014). The unique aroma identified in oriental sweet melon is attributed to several volatile compounds including alcohols, acids, aldehydes, and esters that are biosynthetically derived from FAs, amino acids, carotenoids, and terpenes (Aubert and Bourger, 2004; Beaulieu and Grimm, 2001). In general, FAs are considered to be major precursors of aroma volatiles in melon [Cucumis melo (Flores et al., 2002)]. Straight-chain esters are produced from free FA such as LA, $\mathrm{LeA}$, and $\mathrm{OA}$ by the generation of short-chain alcohols and aldehydes through $\beta$-oxidation, hydroperoxyacid cleavage, and the LOX pathways (Schwab et al., 2008).

Lipoxygenase and HPL are important enzymes produced by the LOX pathway, which is responsible for the synthesis of

Received for publication 19 Jan. 2016. Accepted for publication 31 Mar. 2016. This work was financially supported by the Science and Technology Research Program of Shandong Province (2010GNC10939), Construction Project of Modern Agricultural Industry Technology System of Shandong Province (SDAIT-02-022-08), and Special Fund for Agro-scientific Research in the Public Interest (201203095).

${ }^{1}$ Corresponding author. E-mail: edmonlee@hotmail.com. volatile compounds contributing to "green" and "fresh" notes in ripe fruit (Baldwin et al., 2000). First, LOX produces hydroperoxide isomers of FA, which are subsequently cleaved by HPL to form hexanal and hexenal, respectively. Then, these aldehydes are reduced to alcohols by ADH (Manríquez et al., 2006). AAT catalyzes the final linkage between acyl CoA and alcohol to form esters and, thus, is directly responsible for the production of esters (Khanom and Ueda, 2008).

The plant hormone ETH controls most ripening events in fruit, and consequently, also controls most of the metabolic pathways responsible for the development of sensory quality (Giovannoni, 2004; Klee and Giovannoni, 2011). FA levels are highly regulated during fruit development and especially accumulate during fruit ripening, particularly during the climacteric peak (Song and Bangerth, 2003). It is well known that biosynthesis of some volatile compounds is regulated by ETH. Melon has climacteric and nonclimacteric genotypes (Beaulieu, 2005; Flores et al., 2002; Pech et al., 2008). Typical climacteric phenotypes with high ETH production are often highly aromatic (Périn et al., 2002; Portnoy et al., 2008; Shalit et al., 2001; Wyllie and Leach, 1992), whereas nonclimacteric melon is consistently less aromatic and unable to produce autocatalytic ETH (Burger et al., 2006). 
Although the FA pathway is important for the production of aroma volatile compounds, the hormonal factor of ETH regulating this biosynthetic pathway in oriental sweet melon have received relatively little attention. Therefore, the objective of the present study was to explore the potential biochemical steps involved in the biosynthesis of straight-chain aroma volatiles from FA under ETH regulation.

\section{Materials and Methods}

Plant material and treatments. The oriental sweet melons used in this study $(n=220)$ consisted of two cultivars, orange-fleshed Caihong7 (a highly aromatic cultivar) and green-fleshed Tianbao (a less aromatic cultivar). The former is oval in shape, whereas the latter is round. The individual fruit of both cultivars weigh $\approx 0.4 \mathrm{~kg}$. In general, 'Caihong7' requires $\approx 33 \mathrm{~d}$ after anthesis (DAA) whereas 'Tianbao' requires $35 \mathrm{DAA}$ to achieve the final ripening stage of development (i.e., the ripening stage occurs after the fruit change in firmness, peel color, and soluble solid content and the abscission zone develops) (Li et al., 2011; Qi et al., 2011). One plant was grown per pot (volume of $25 \mathrm{~L}$, soil:peat:compost $=1: 1: 1$ ) from Apr. 2012 to July 2012 in a greenhouse at the Horticultural Research Center, Shenyang Agricultural University, Shenyang, People's Republic of China. Freshly opened female flowers were sprayed with the growth regulator [Fengchanji2, a hormone complex mainly containing 4-chlorophenoxyacetic acid, which can increase fruit setting rates (Shenyang Agricultural University)] and tagged on the day of bloom. Oriental sweet melons were cultivated as single stems, with two or three fruit per vine and were harvested at 24 DAA (mature-green stage) at the same node of the plant at a physiologically mature stage.

After harvest, fruit were carefully inspected for bruising and compression damage. Only fruit without visual defects and uniform shapes and sizes were selected for processing and randomly divided into three lots, and with a mount of 90 oriental sweet melon fruit of each cultivar per lot. Lot 1 was left intact (control), Lot 2 was treated with $1 \mathrm{mg} \cdot \mathrm{L}^{-1} 1$ methylcyclopropene [1-MCP $\left(0.14 \%\right.$ w/v, SmartFresh ${ }^{\text {TM}}$; Rohm and Hass, Philadelphia, PA)], and Lot 3 was treated with $8000 \mu \mathrm{L} \cdot \mathrm{L}^{-1}$ ETH on the day of harvest (day 0 ). Three replicates, with five fruit for each replicate, were selected at random from each treatment (ETH, 1-MCP, or control). Oriental sweet melons of Lots 2 and 3 were placed in 30-L airtight chambers and treated with ETH and 1-MCP, respectively, at (mean \pm SD) $23 \pm 1{ }^{\circ} \mathrm{C}$ and $62 \% \pm 1 \%$ relative humidity controlled by an air conditioner. The chamber was sealed for $24 \mathrm{~h}$ and then ventilated for $2 \mathrm{~h}$ to eliminate any trace of ETH or 1-MCP. Fruit fumigated with distilled water was used as a control. Control and ETH-/ 1-MCP-treated fruit were kept in separate storage areas at $23{ }^{\circ} \mathrm{C}$ to avoid possible contamination by ETH or 1-MCP outgassing. Sampling was conducted from day 1 ( $24 \mathrm{~h}$ after treatment) to day 15 at 3-d intervals. On day 9, subsets (20 fruit) of the ETHand 1-MCP-treated oriental sweet melon from each cultivar were then treated with 1-MCP or ETH for $24 \mathrm{~h}$ (day 1) at $23^{\circ} \mathrm{C}$, separately, and after that, sampled on days 3 and 6. All epidermal (peel) and hypodermal mesocarp (flesh) tissue samples were separated using a peeler with a sharp stainless steel blade. Although avoiding excess flesh, the peel of each oriental sweet melon was sampled to a depth of $\approx 1.5 \mathrm{~mm}$. All peel and flesh samples were immediately frozen in liquid nitrogen and stored at $-80{ }^{\circ} \mathrm{C}$.
MEASUREMENT OF ETH PRODUCTION RATE. The methodology for ETH production rate was based on the method of Liu et al. (2012) with modification. ETH production rate was measured by withdrawing $100 \mu \mathrm{L}$ samples of internal gas from the seed cavity of each oriental sweet melon and injecting it into a gas chromatograph (Varian GC-3800; Agilent Technologies, Palo Alto, CA), equipped with a flame ionization detector and a GDX-102 column $(3 \mathrm{~m} \times 2 \mathrm{~mm}$ i.d.; Dalian Institute of Chemical Physics, Dalian, China) at $100{ }^{\circ} \mathrm{C}$, using nitrogen as a carrier gas $\left(20 \mathrm{~mL} \cdot \mathrm{min}^{-1}\right)$. Injector and detector temperatures were 250 and $120^{\circ} \mathrm{C}$, respectively. ETH was quantified by peak area, and external standards were used for calibration. The calibration curve was linear when the concentration of ETH was in the range of $10 \%$ to $50 \% \mathrm{v} / \mathrm{v}$ (microliters per liter) $(r=$ 0.998).

Volatile analysis: Headspace formation, SOlid-PHaSe MICRO-EXTRACTION, GAS CHROMATOGRAPHY-MASS SPECTROMETRY ANALYSIS. Frozen oriental sweet melon samples ( $100 \mathrm{~g}$ of flesh or $50 \mathrm{~g}$ of peel) were thawed at room temperature for $30 \mathrm{~min}$. Fresh juice was squeezed with a juicer (JYL-C05; Joyoung Co., Jinan, China), and juice samples were taken by filtering juice through a glass funnel and four layers of cheesecloth. Then $3.5 \mathrm{~g}$ sodium chloride (analytical grade) and an internal standard $\left(50 \mu \mathrm{L}\right.$ of octan-1-ol, $59.5 \mathrm{mg} \cdot \mathrm{L}^{-1}$, $0.5 \% \mathrm{v} / \mathrm{v}$; Aladdin Chemistry Co., Tianjin, China) were added to $10 \mathrm{~mL}$ supernatant of the juice. The mixture was homogenized completely and poured into a $20-\mathrm{mL}$ glass vial (Thermo Fisher Scientific, Waltham, MA). Solid-phase micro-extraction was used to extract the volatile components of oriental sweet melon. The volatile compounds were analyzed by gas chromatography-mass spectrometry (Trace GC-Ultra-ITQ 900; Thermo Fisher Scientific) using a TR-5ms SQC column $(30 \mathrm{~m} \times 0.25 \mathrm{~mm}$ i.d. $\times 0.25 \mu \mathrm{m}$ thickness; Thermo Fisher Scientific) and 40-min runs. A sample from five fruit was measured, and the experiment was repeated three times. The detailed procedure was as described by Liu et al. (2012).

The data analysis of chromatographic aroma was processed by using Xcalibur ${ }^{\circledR} 2.0$ (Thermo Fisher Scientific). The volatile compounds detected in the oriental sweet melon fruit have been identified by comparing their mass spectra with those included in the National Institute for Standards and Technology (NIST05 search version 2.0) data bank and by comparing with linear retention indices reported in the literature or NIST database (Chaparro-Torres et al., 2015; Dos-Santos et al., 2013; ObandoUlloa et al., 2008). In addition, the Chemical Abstract Service numbers of the volatiles reported in the NIST98 database were used to obtain their corresponding International Union of Pure and Applied Chemistry name. Quantitative analysis of individual compounds was performed using the peak area of the internal standard of octan-1-ol. When data were not detected, empty cells were automatically considered as zero for the analysis (Allwood et al., 2014; Dos-Santos et al., 2013). Results were expressed as micrograms per gram.

FAs ANALYsis. The total FA profile was determined by FA methyl ester analysis, and the total lipid fractions were extracted from $5 \mathrm{~g}$ of flesh and peel tissues based on the method of Nie et al. (2005) and Zhang et al. (2009) with modifications. Briefly, the lipids were extracted with petroleum ether:ether $(4: 3, \mathrm{v} / \mathrm{v})$ for $24 \mathrm{~h}$ at $0-4{ }^{\circ} \mathrm{C}$. After that, methyl esterification was done by adding $10 \mathrm{~mL}$ of potassium hydroxide-methanol solution $\left(0.4 \mathrm{~mol} \cdot \mathrm{L}^{-1}\right)$ for $2 \mathrm{~h}$ at room temperature. Then, it was centrifuged at $4000 g_{\mathrm{n}}$ for $10 \mathrm{~min}$. The upper organic phase was 
recovered and analyzed in a gas chromatograph (Varian GC-3800), equipped with a CP 7485 column $(25 \mathrm{~m} \times 0.32 \mathrm{~mm}$ i.d. $\times$ $0.52 \mu \mathrm{m}$ thickness; Dalian Institute of Chemical Physics). Conditions for chromatography were $1 \mu \mathrm{L}$ of injection, split injection (split ratio 30:1), and nitrogen as gas carrier. The injector and detector temperature were at 240 and $250{ }^{\circ} \mathrm{C}$. Initial oven temperature started at $100{ }^{\circ} \mathrm{C}$ held for $1 \mathrm{~min}$, increased to $205^{\circ} \mathrm{C}$ at $8{ }^{\circ} \mathrm{C} \cdot \mathrm{min}^{-1}$ held for $0.1 \mathrm{~min}$, increased to $240{ }^{\circ} \mathrm{C}$ at $3{ }^{\circ} \mathrm{C} \cdot \mathrm{min}^{-1}$ held for $10 \mathrm{~min}$, with $20 \mathrm{~min}$ of total running time. Identification of standard compounds was confirmed by a comparison of collected mass spectra with those of authenticated reference.

EnZYMe ACTIVITIES. LOX activity was determined as previously described (Chen et al., 2003; Liu et al., 2012) with some modifications. Oriental sweet melon flesh and peel tissues [ $3 \mathrm{~g}$ fresh weight $(\mathrm{FW})]$ were ground to a fine powder in $8 \mathrm{~mL}$ of $50-\mathrm{mmol} \cdot \mathrm{L}^{-1}$ potassium phosphate buffer ( $\left.\mathrm{pH} 7.0\right)$. The homogenate was centrifuged at $15,000 g_{\mathrm{n}}$ for $15 \mathrm{~min}$ at $4{ }^{\circ} \mathrm{C}$. The supernatant was analyzed using LA as the substrate by an ultraviolet/visible spectrophotometer (Cary 100; Agilent Technologies). The reaction was started by addition of $0.2 \mathrm{~mL}$ of crude tissue extract to $25 \mu \mathrm{L}$ of substrate containing $2.775 \mathrm{~mL}$ of $0.1 \mathrm{~mol} \cdot \mathrm{L}^{-1}$ sodium acetate buffer ( $\mathrm{pH} 6.0$ ) as reaction buffer. The increase in absorbance at $234 \mathrm{~nm}$ was measured to monitor the formation of conjugated dienes. One activity unit (U) was defined as the increase in one unit of absorbance per minute, and results were expressed as specific activity (milliunits per milligram protein).

HPL activity was assayed using the method of Salas and Sanchez (1999) with some modifications. Oriental sweet melon flesh and peel tissues ( $3 \mathrm{~g} \mathrm{FW}$ ) were ground to a fine powder in $6 \mathrm{~mL}$ of $150-\mathrm{mmol} \cdot \mathrm{L}^{-1}$ HEPES-KOH buffer $(\mathrm{pH} \mathrm{8.0)}$. The homogenate was centrifuged at $15,000 g_{\mathrm{n}}$ for $30 \mathrm{~min}$ at $4{ }^{\circ} \mathrm{C}$. In the final volume of $3.5 \mathrm{~mL}$, the following were present: $2 \mathrm{~mL}$ of $150-\mathrm{mmol} \cdot \mathrm{L}^{-1}$ HEPES-KOH $(\mathrm{pH} 8.0), 0.75 \mathrm{~mL}$ of LA hydroperoxide sodium substrate, $0.15 \mathrm{~mL}$ of $1.6-\mathrm{mmol} \cdot \mathrm{L}^{-1}$ nicotinamide adenine dinucleotide hydrogen, $0.1 \mathrm{~mL} \mathrm{ADH}$ enzyme liquid $\left(0.5 \mathrm{mg} \cdot \mathrm{mL}^{-1}\right.$ borate buffer, $\left.\mathrm{pH} 8.6\right)$, and $0.5 \mathrm{~mL}$ of crude tissue. Reaction velocities were determined from the decline in absorbance at $340 \mathrm{~nm}$.

Oriental sweet melon flesh and peel tissues (3 g FW) were homogenized with mortar and pestle in $2.4 \mathrm{~mL}$ of $100-\mathrm{mmol} \cdot \mathrm{L}^{-1} \mathrm{MES}-$ Tris buffer $(\mathrm{pH} 6.5)$ containing $2 \mathrm{mmol} \cdot \mathrm{L}^{-1}$ dithiothreitol and $1 \%(\mathrm{w} / \mathrm{v})$ of polyvinylpyrrolidone. After filtration and centrifugation $\left(15,000 \mathrm{~g}_{\mathrm{n}}, 4{ }^{\circ} \mathrm{C}\right)$ for $30 \mathrm{~min}$, the supernatant was recovered and used for the ADH enzyme assay as previously described by Longhurst et al. (1990).

Oriental sweet melon flesh or peel tissues ( $3 \mathrm{~g} \mathrm{FW})$ were homogenized with mortar and pestle in $6 \mathrm{~mL}$ of $100-\mathrm{mmol} \cdot \mathrm{L}^{-1}$ potassium Tris-HCI ( $\mathrm{pH}$ 8.0) and $1 \mathrm{mg} \cdot \mathrm{g}^{-1}$ of polyvinyl polypyrrolidone. After filtration and centrifugation $\left(16,000 \mathrm{~g}_{\mathrm{n}}\right.$, $4{ }^{\circ} \mathrm{C}$ ) for $30 \mathrm{~min}$, the supernatant was recovered and used for the AAT enzyme assay as previously described by Fellman et al. (2000). The protein concentration of enzyme extracts was determined using the method described by Bradford (1976).

RNA ISOLATION. Total RNA from fruit samples was extracted based on the method of Li et al. (2016) and Tian et al. (2012). Peel and flesh tissues ( $3 \mathrm{~g}$ each) were ground in liquid nitrogen using a baked mortar and pestle. The ground powder was transferred to $50-\mathrm{mL}$ polypropylene tubes with $15 \mathrm{~mL}$ of guanidine isothiocyanate extraction buffer that had been previously incubated at $65{ }^{\circ} \mathrm{C}$. Tubes were briefly vortexed for
$1 \mathrm{~min}$, and samples were separated with a centrifuge (Biospec Products, Bartlesville, OK) at $12,000 g_{\mathrm{n}}$. The supernatant was mixed with $1.5 \mathrm{~mL}$ of $2 \mathrm{~mol} \cdot \mathrm{L}^{-1}$ sodium acetate, $15 \mathrm{~mL}$ of water-saturated phenol, and $3 \mathrm{~mL}$ of chloroform:isoamyl alcohol $(24: 1, \mathrm{v} / \mathrm{v})$. The tubes were inverted for mixing and then incubated at $4{ }^{\circ} \mathrm{C}$ for $15 \mathrm{~min}$. Each mixture was centrifuged at $12,000 g_{\mathrm{n}}$ for $20 \mathrm{~min}$ at $4{ }^{\circ} \mathrm{C}$, and the supernatant was transferred to a clean tube. A half volume of water-saturated phenol and chloroform:isoamyl alcohol was added to this solution, and the mixture was again centrifuged for $20 \mathrm{~min}$. After repeating the chloroform extraction process, an equal volume of isopropyl alcohol was added to the mixture, and the RNA was allowed to precipitate at $-20{ }^{\circ} \mathrm{C}$ for $45 \mathrm{~min}$ before centrifugation at $12,000 g_{n}$ for $20 \mathrm{~min}$. The supernatant was discarded, and the RNA pellet was washed twice with $3 \mathrm{~mL}$ of $75 \%$ ethanol. After washing, the tubes were centrifuged at $12,000 g_{\mathrm{n}}$ for $5 \mathrm{~min}$ at $4{ }^{\circ} \mathrm{C}$. The precipitate was dissolved in $1 \mathrm{~mL}$ of RNase-free water and one-third volume of $10 \mathrm{~mol} \cdot \mathrm{L}^{-1}$ lithium chloride was added. Extracts were stored at $-20{ }^{\circ} \mathrm{C}$ overnight. The total RNA concentration was determined using a spectrophotometer (NanoDrop ND-100; Thermo Fisher Scientific), and the RNA quality was verified by agarose gel electrophoresis.

QuANTITATIVE REAL-TIME POLYMERASE CHAIN REACTION. DNasetreated RNA ( $3 \mu \mathrm{g}$ ) was reverse transcribed in a reaction volume of $20 \mu \mathrm{L}$ using the Omniscript Reverse Transcription Kit (Tiangen, Beijing, China) (Li et al., 2016; Tian et al., 2012). Real-time quantitative polymerase chain reaction (qPCR) was performed using $100 \mathrm{ng}$ of total RNA in a $20-\mu \mathrm{L}$ reaction volume with the SYBR Green PCR MasterMix (PE-Applied Biosystems, Foster City, CA) on an ABI PRISM 7500 real-time PCR (RT-PCR) system. The sequences of all primers used for qPCR are described in Table 1. The RT-PCR conditions were as follows: 40 cycles of $94^{\circ} \mathrm{C}$ for 4 min followed by $94^{\circ} \mathrm{C}$ for $25 \mathrm{~s}$ and $60{ }^{\circ} \mathrm{C}$ for $30 \mathrm{~s}$.

Statistical analysis. Experiments were performed in a completely randomized design. All individual volatile compounds data for different tissues from both treated and control oriental sweet melon fruit were log transformed to improve normality (Bernillon et al., 2013), and then, were submitted to an analysis of variance (ANOVA), using SPSS 11.0 (IBM Co., Armonk, NY), and two factors with treatment and time and interaction and $P$ values were estimated following StudentNewman-Keuls's multiple range tests. The charts were performed by using Origin (version 7.5; Microcal Software, Northampton, MA). Levels of straight-chain aroma volatile compounds and FA as well as aroma-related enzymes for peel tissue from both treated and control 'Caihong7' and 'Tianbao' oriental sweet melon fruit are reported in supplemental data.

\section{Results}

RATE OF ETH PRODUCTION. The rate of ETH production was increased by ETH treatment but was inhibited by 1-MCP in both cultivars (Fig. 1). Moreover, the climacterics of the ETH production rate in ETH-treated and control fruit of Caihong7 developed $3 \mathrm{~d}$ earlier than in Tianbao, and significantly higher values were observed in the former cultivar than in the latter. According to the ANOVA data, the combined treatment did not result in significantly different effects, apart from 1-MCP + ETH-treated 'Caihong7'. 
Table 1. Sequence of primers used for gene expression analysis in peel and flesh tissues of 'Caihong7' and 'Tianbao' oriental sweet melon fruit by real-time quantitative polymerase chain reaction.

\begin{tabular}{|c|c|}
\hline Primer $^{\mathrm{Z}}$ & Oligonucleotide sequence \\
\hline Cm-actin-344 (F) & 5'-GTGATGGTGTGAGTCACACTGTTC-3' \\
\hline Cm-actin-426 (R) & 5'-ACGACCAGCAAGGTCCAAAC-3' \\
\hline$C m-A D H 1-518(\mathrm{~F})$ & 5'-GTGTTCTTAGCTGCGGCATTT-3' \\
\hline$C m-A D H 1-588(\mathrm{R})$ & 5'-TTGACCCTTTTTAGGCTTTGCA-3' \\
\hline$C m-A D H 2-145(\mathrm{~F})$ & 5'-GCGGAATCGTTAAAGGGTGTACT-3' \\
\hline$C m-A D H 2-216(\mathrm{R})$ & 5'-AGCCGCCTCTCTCTCTTCTTC-3' \\
\hline$C m-A A T 1-1181(\mathrm{~F})$ & 5'-CCACAGGGGCCAGAATTACA-3' \\
\hline$C m-A A T 1-1284(\mathrm{R})$ & 5'-TGGAGGAGGCAAGCATAGACTT-3' \\
\hline$C m-A A T 2-1175(\mathrm{~F})$ & 5'-CTATAATTGGAGGGTGTGGAATTATC-3' \\
\hline$C m-A A T 2-1311(\mathrm{R})$ & 5'-AACATTTGCCCTAAATCTTTCCAT-3' \\
\hline$C m-A A T 3-677(\mathrm{~F})$ & 5'-CGCTTGATGACATGGCACAT-3' \\
\hline$C m-A A T 3-744(\mathrm{R})$ & 5'-GGCCTTACGGATAGCAGAGATC-3' \\
\hline$C m-A A T 4-659(\mathrm{~F})$ & 5'-CAGTTGTACCCCCGTCGAGTA-3' \\
\hline Cm-AAT4-734 (R) & 5'-AATATCGCTTCTGATCGGAACAC-3' \\
\hline
\end{tabular}

${ }^{\mathrm{z}} \mathrm{ADH}=$ alcohol dehydrogenase; AAT $=$ alcohol acetyltransferase; $\mathrm{F}=$ forward primer; $\mathrm{R}=$ reverse primer. GenBank accession numbers: $C m-A D H 1$ (ABC02081), $C m-A D H 2$ (ABC02082), $C m-A A T 1$ (CAA94432), Cm-AAT2 (AAL77060), Cm-AAT3 (AAW51125), and Cm-AAT4 (AAW 51126).

middle stages of storage and maximal production on day 12 (Fig. 3). Increasing trends were observed throughout the experimental period in the ETH-treated and control 'Tianbao' fruit. Compared with the controls, 1-MCP effectively suppressed the production of straightchain esters in both 'Caihong7' and 'Tianbao' $(P<0.05)$, thereby leading to relatively lower levels of straight-chain ester accumulation. Additionally, 1-MCP + ETH did not completely reverse the original trend of volatiles observed in their corresponding treated fruit.

Straight-chain esters in the peel and flesh tissues of ETH-/1-MCPtreated or control 'Caihong7' and 'Tianbao' fruit were predominantly composed of acetate esters; in particular, 'Caihong7' contained a large

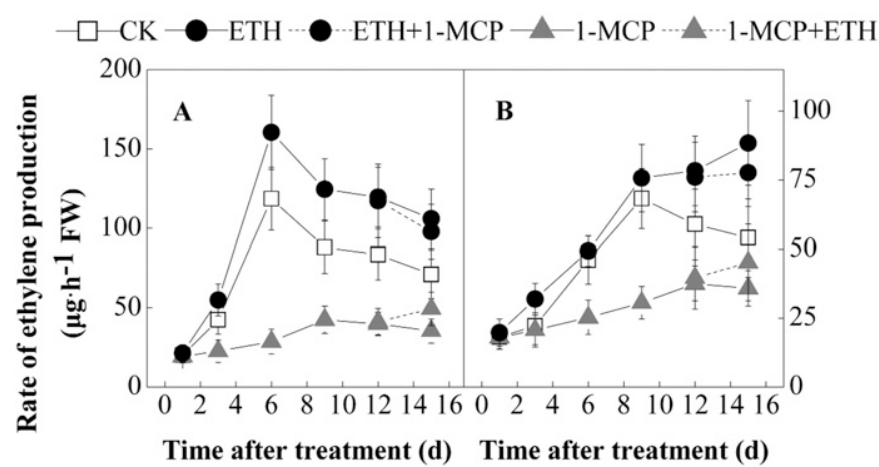

Fig. 1. Effects of ethylene (ETH) and 1-methylcyclopropene (1-MCP) on ETH production rates in (A) 'Caihong7' and (B) 'Tianbao' oriental sweet melon fruit during storage at room temperature $\left(23^{\circ} \mathrm{C}\right)$ for up to $15 \mathrm{~d}$. Values are means $\pm \mathrm{SE}(\mathrm{n}=3)$. Distilled water was the control $[\mathrm{CK}(\square)], 10 \mathrm{mg} \cdot \mathrm{L}^{-1}$ ETH treatment $(\bullet), 1 \mathrm{mg} \cdot \mathrm{L}^{-1} 1$-MCP $(\boldsymbol{\Delta}), \mathrm{ETH}$ followed by 1 -MCP $(\mathrm{ETH}+$ $1-\mathrm{MCP}, \ldots \bullet \ldots)$, and 1-MCP followed by ETH $(1-\mathrm{MCP}+\mathrm{ETH}, \ldots \boldsymbol{\Lambda} \ldots)$.

STRAIGHT-CHAIN AROMA VOLATILES PRODUCTION. Three alcohols and two aldehydes with six straight-chain carbons were identified in the headspace of the 'Caihong7' and 'Tianbao' fruit. Moreover, higher levels of aldehydes and alcohols were found in 'Tianbao' compared with those in 'Caihong7' fruit after ETH or 1-MCP treatment. The concentrations of aldehydes and alcohols gradually decreased with longer duration of storage in ETH-/1-MCP-treated and untreated 'Caihong7' and 'Tianbao' fruit (Tables 2 and 3; Fig. 2; Supplemental Tables 1 and 2; Supplemental Fig. 1). The total levels of aldehydes were significantly higher in 1-MCP-treated fruit from both cultivars than in ETH-treated and control fruit after $9 \mathrm{~d}$ of storage $(P<0.05)$. In contrast, the total levels of straight-chain alcohols was significantly higher in ETHtreated samples but was significantly lower in 1-MCP-treated samples, especially after $6 \mathrm{~d}$ of storage $(P<0.05)$ from both cultivars.

There were moderate ester production rates in the ETHtreated and control 'Caihong7' fruit at the initial stages of storage, with rapid increases in this production during the amount of ethyl acetate. The ethyl acetate content in the peel and flesh of ETH-treated 'Caihong7', was about six and four times higher than that of the corresponding 1-MCP-treated tissues and reached maximal values on days 15 and 12 of storage, respectively (Table 2; Supplemental Table 1). The majority of the levels of acetate, hexanoate, and hexyl esters, such as ethyl acetate, butyl acetate, hexyl acetate, ethyl hexanoate, butyl hexanoate, $(Z)$-hex-2-enyl acetate, and $(E)$ 2-hexenyl butanoate, tended to vary coinciding with the change of ETH production rate in ETH-/1-MCP-treated or untreated 'Caihong7' and 'Tianbao' fruit (Tables 2 and 3; Supplemental Tables 1 and 2). Most butyrate levels followed an increasing trend in both ETH-/1-MCP-treated and untreated 'Caihong7' and 'Tianbao' fruit throughout the postharvest period.

FA Content. In our study, the major FA component identified in oriental sweet melon fruit was LeA, followed by LA and then OA. As shown in Fig. 4 and Supplemental Fig. 2, the FA content was significantly higher in Tianbao than in Caihong7, except for the level of OA measured in the peel from the latter cultivar. Further, a higher FA content was found in peel tissues than in flesh tissues from both cultivars $(P<0.05)$. The data showed that the levels of FA gradually decreased in peel and flesh tissues of ETH-/1-MCP-treated and control 'Caihong7' fruit during storage. Conversely, the content of OA was highest on day 6 in peel and flesh tissues of ETHtreated 'Tianbao' fruit, and LeA and LA concentrations reached maximum levels on day 9. In the 1-MCP-treated fruit, the levels of LA and OA were significantly lower than those in control $(P<0.05)$, and this was higher than those of ETH-treated fruit.

ENZYME ACTIVITY. LOX activity reached maximal levels on days 9 and 6 in all tissues in ETH-treated and control 'Caihong7' fruit, respectively (Fig. 5A and B; Supplemental Fig. 3). However, the peak LOX activity of control 'Caihong7' fruit was much lower than that of ETH-treated fruit. The LOX activity peaked on day 9 in all tissues in ETH-treated and control 'Tianbao' fruit.

HPL activity peaked after $3 \mathrm{~d}$ of treatment, and then decreased in all tissues of 'Caihong7' fruit (Fig. 5C and D), whereas it fluctuated and then peaked on day 9 in samples of treated and control 'Tianbao' fruit. 


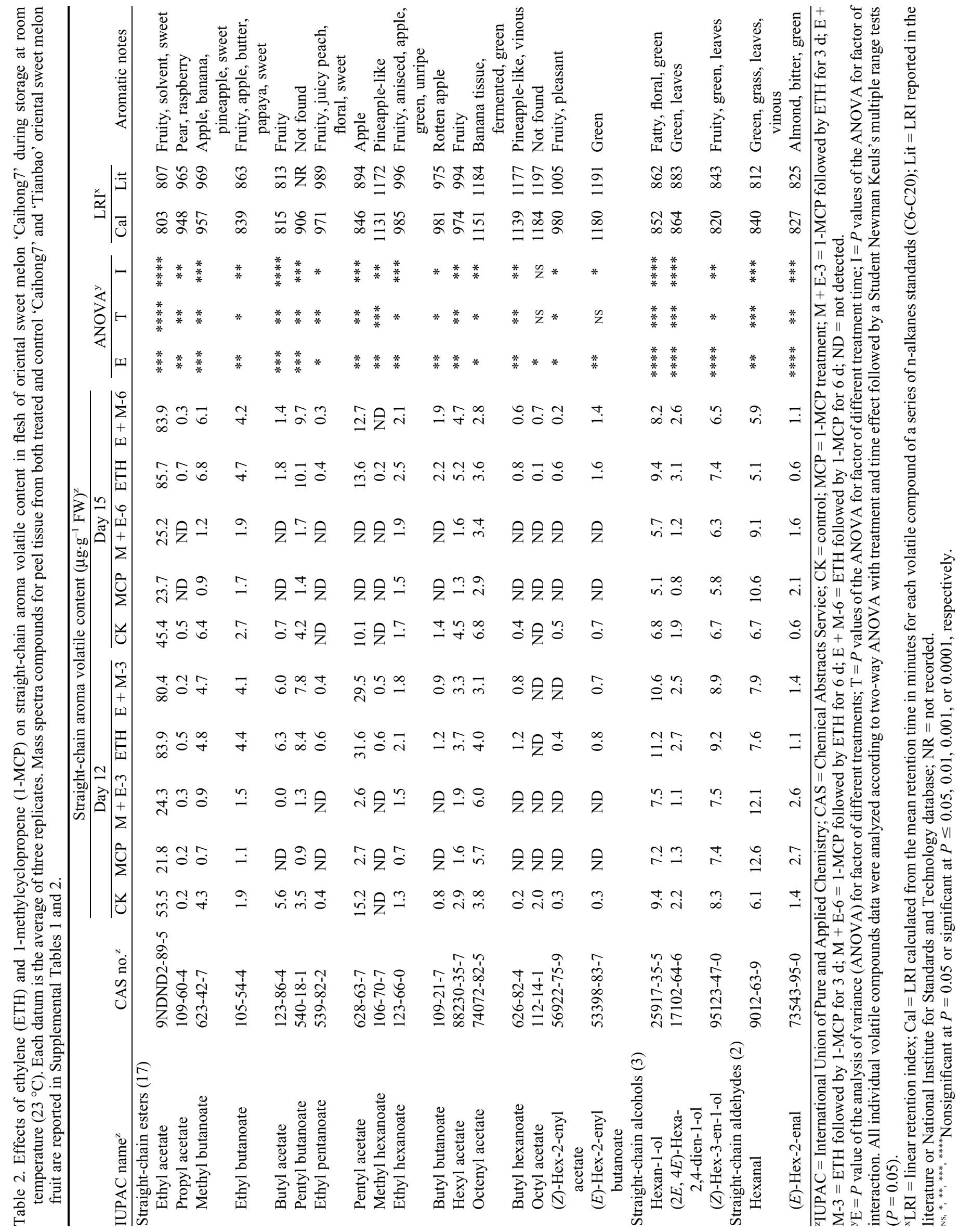




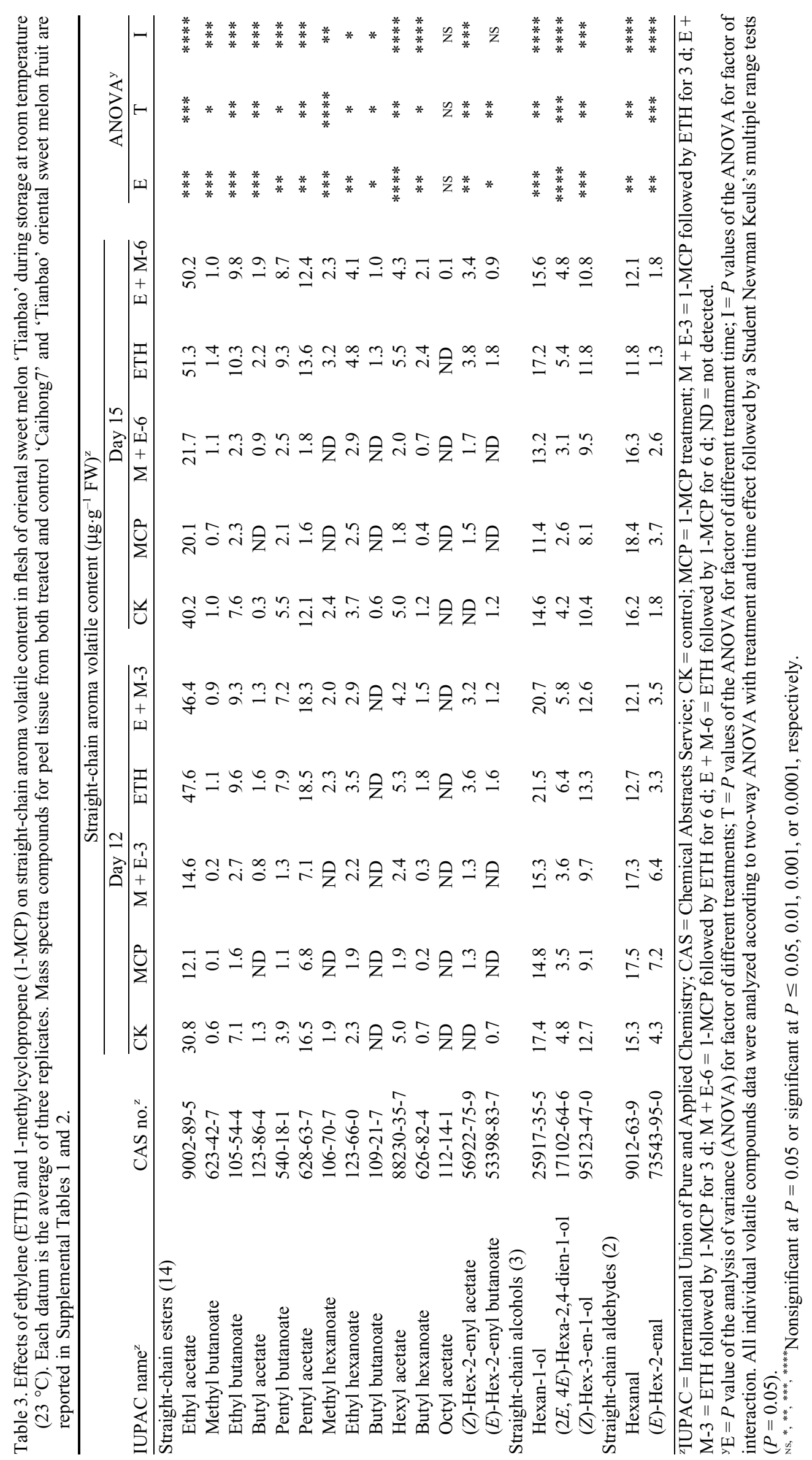




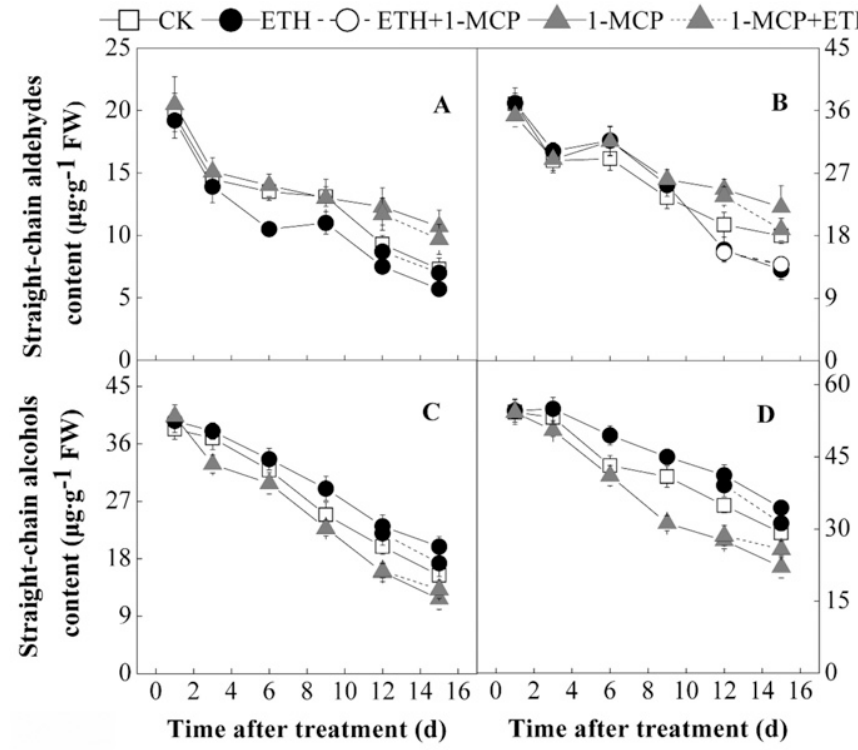

Fig. 2. Effects of ethylene (ETH) and 1-methylcyclopropene (1-MCP) on content of $(\mathbf{A}, \mathbf{B})$ straight-chain aldehydes and $(\mathbf{C}, \mathbf{D})$ alcohols in flesh tissues of 'Caihong7' (left) and 'Tianbao' (right) oriental sweet melon fruit during storage at room temperature $\left(23^{\circ} \mathrm{C}\right)$ for up to $15 \mathrm{~d}$. Values are means $\pm \mathrm{SE}$ $(\mathrm{n}=3)$. Distilled water was the control $[\mathrm{CK}(\square)], 10 \mathrm{mg} \cdot \mathrm{L}^{-1} \mathrm{ETH}$ treatment $(\bullet)$, $1 \mathrm{mg} \cdot \mathrm{L}^{-1} 1-\mathrm{MCP}(\boldsymbol{\Lambda})$, ETH followed by $1-\mathrm{MCP}(\mathrm{ETH}+1-\mathrm{MCP}, \ldots \bullet \ldots)$, and 1-MCP followed by ETH (1-MCP + ETH, ... $\mathbf{\Delta} \ldots)$.

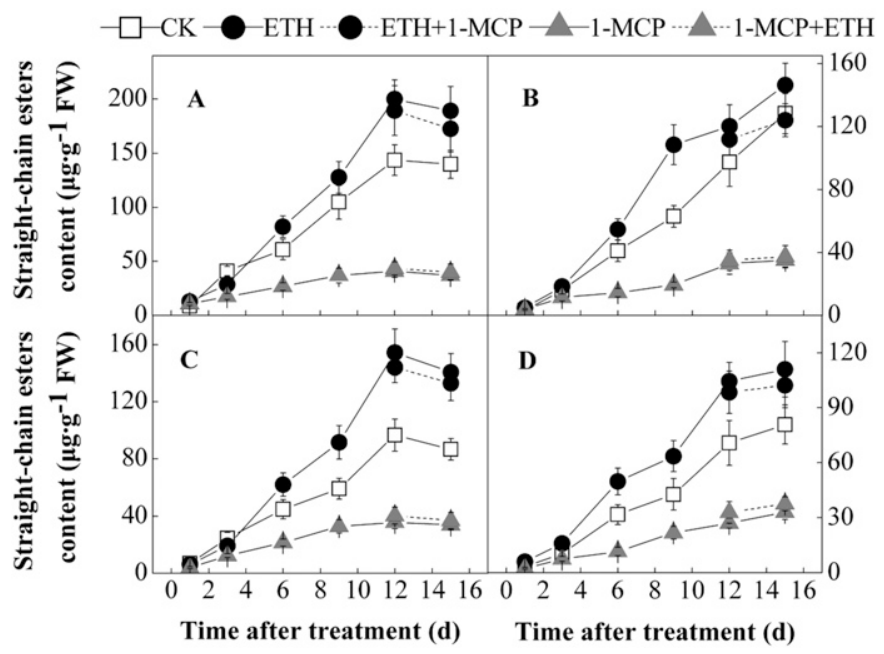

Fig. 3. Effects of ethylene (ETH) and 1-methylcyclopropene (1-MCP) on content of (A-D) straight-chain esters in peel (upper) and flesh (lower) tissues of 'Caihong7' (left) and 'Tianbao' (right) oriental sweet melon fruit during storage at room temperature $\left(23^{\circ} \mathrm{C}\right)$ for up to $15 \mathrm{~d}$. Values are means $\pm \mathrm{SE}(\mathrm{n}=$ $3)$. Distilled water was the control [CK $(\square)], 10 \mathrm{mg} \cdot \mathrm{L}^{-1} \mathrm{ETH}$ treatment $(\bullet)$ $1 \mathrm{mg} \cdot \mathrm{L}^{-1} 1-\mathrm{MCP}(\boldsymbol{\Delta})$, ETH followed by $1-\mathrm{MCP}(\mathrm{ETH}+1-\mathrm{MCP}, \ldots \bullet \ldots)$, and 1-MCP followed by ETH $(1-\mathrm{MCP}+\mathrm{ETH}, \ldots \boldsymbol{\Lambda} \ldots)$.

ADH activity increased rapidly during the first $6 \mathrm{~d}$ of postharvest storage, and then reached maximal levels on day 6 in all tissues of ETH-treated and control 'Caihong7' fruit as well as the ETH-treated 'Tianbao' fruit (Fig. 5E and F). The activity of this enzyme then decreased over the rest of the monitoring period, thereby showing an overall declining trend for both cultivars.

A sharp increase in AAT activity was observed on days 9 and 12 in peel and flesh tissues of ETH-treated/control fruit of

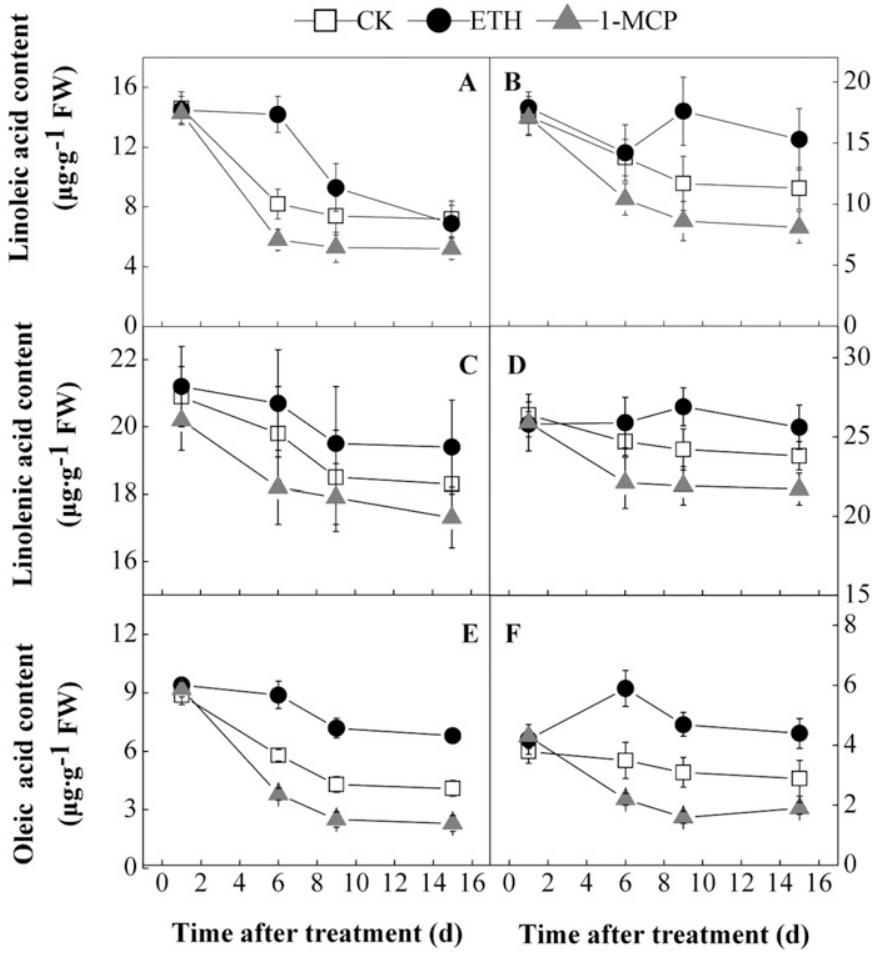

Fig. 4. Effects of ethylene (ETH) and 1-methylcyclopropene (1-MCP) on (A, B) linoleic acid, (C, D) linolenic acid, and $(\mathbf{E}, \mathbf{F})$ oleic acid in flesh tissue of 'Caihong7' (left) and 'Tianbao' (right) oriental sweet melon fruit during storage at room temperature $\left(23^{\circ} \mathrm{C}\right)$ for up to $15 \mathrm{~d}$. Values are means $\pm \mathrm{SE}$ $(\mathrm{n}=3)$. Distilled water was the control $(\mathrm{CK})$.

'Caihong7' and 'Tianbao', respectively (Fig. 5G and H). AAT activity further showed similar patterns in all tissues of both cultivars subjected to different treatments.

The enzymatic activity was relatively higher in ETH-treated fruit throughout the storage period compared with the control fruit of both cultivars. In general, most of the 1-MCP-treated fruit exhibited lower levels of enzymatic activity compared with control. ETH + 1-MCP treatment reduced the HPL, ADH, and AAT activities compared with those of fruit treated with ETH alone in peel and flesh of 'Caihong7' and 'Tianbao'. Conversely, the opposite tendency was found in peel and flesh of 'Caihong7' and 'Tianbao' treated with 1-MCP + ETH.

GENE EXPRESSION. Apart from day 6 samples, the expression of $C m-A D H 1$ was significantly higher in peel and flesh tissues of 'Tianbao' than in the corresponding tissues of 'Caihong7' $(P<0.05)$. Moreover, the expression of $\mathrm{Cm}-\mathrm{ADH} 2$ showed a similar pattern. After day 6 , the expression of $\mathrm{Cm}-\mathrm{ADH1}$ dramatically decreased in peel tissue of 'Caihong7' fruit treated with ETH and control. A similar expression pattern was observed in flesh tissues of this cultivar (Fig. 6). The transcript levels of $\mathrm{Cm}-\mathrm{ADH} 1$ peaked on day 9 of storage in peel and flesh samples of ETH-treated and control 'Tianbao' fruit, this trend was followed by a decline over the remaining observation period. The expression of $\mathrm{Cm}-\mathrm{ADH} 2$ followed a tendency similar to that of $C m-A D H 1$. The expression patterns of both $C m-A D H$ and $C m-A A T$ were upregulated by ETH during postharvest ripening in peel and flesh tissues. The transcript levels of $\mathrm{Cm}-\mathrm{ADH} 1$ and $\mathrm{Cm}-\mathrm{ADH} 2$ significantly increased after ETH treatment but were significantly suppressed by $1-\mathrm{MCP}$ treatment compared with control $(P<0.05)$. 


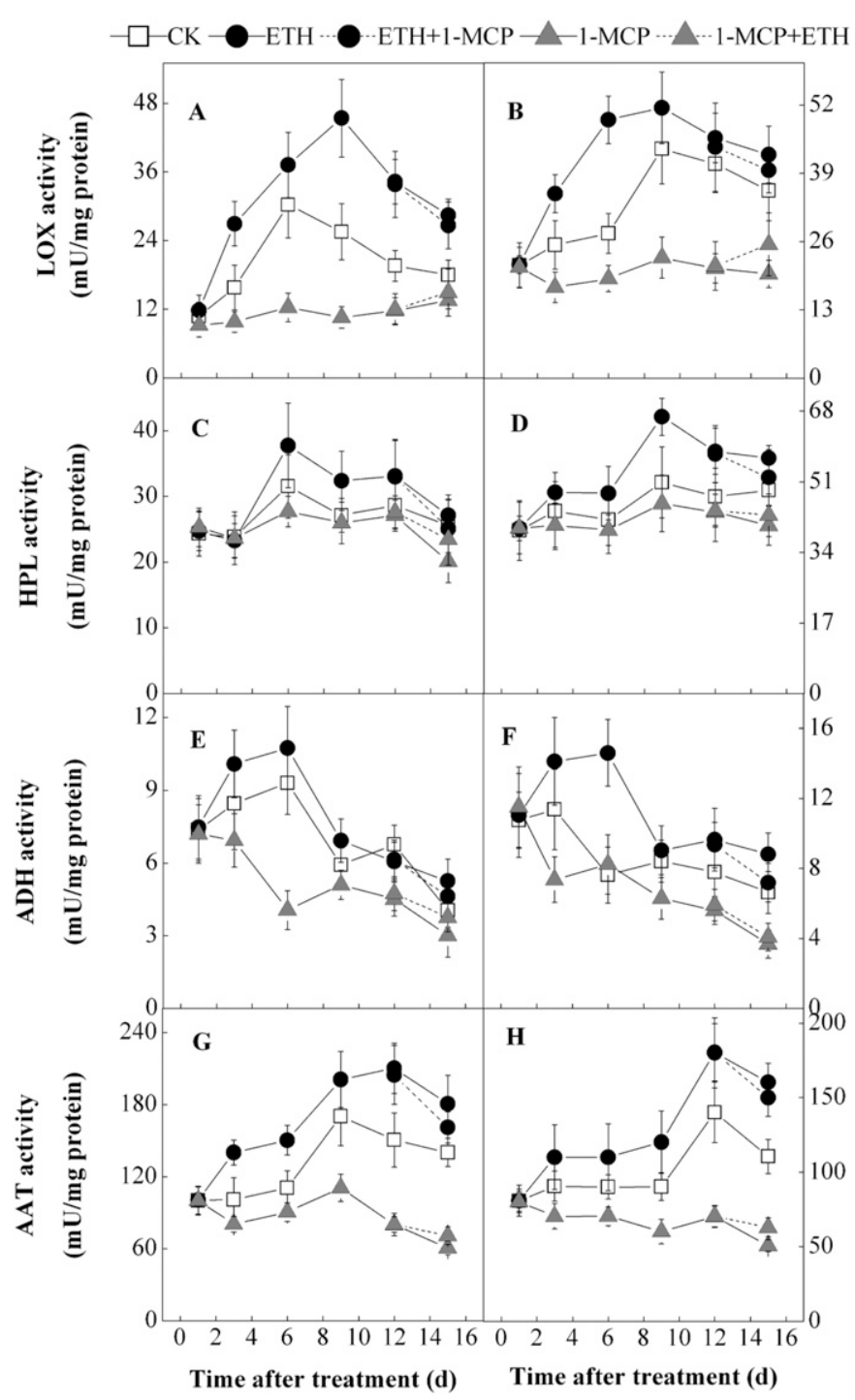

Fig. 5. Effects of ethylene (ETH) and 1-methylcyclopropene (1-MCP) on activities of $(\mathbf{A}, \mathbf{B})$ lipoxygenase, $(\mathbf{C}, \mathbf{D})$ hydroperoxide lyase, $(\mathbf{E}, \mathbf{F})$ alcohol dehydrogenase, and $(\mathbf{G}, \mathbf{H})$ alcohol acetyltransferase in flesh tissue of 'Caihong7' (left) and 'Tianbao' (right) oriental sweet melon fruit during storage at room temperature $\left(23{ }^{\circ} \mathrm{C}\right)$ for up to $15 \mathrm{~d}$. Values are means $\pm \mathrm{SE}$ $(\mathrm{n}=3)$. Distilled water was the control $[\mathrm{CK}(\square)], 10 \mathrm{mg} \cdot \mathrm{L}^{-1} \mathrm{ETH}$ treatment $(\bullet)$, $1 \mathrm{mg} \cdot \mathrm{L}^{-1} 1-\mathrm{MCP}(\boldsymbol{\Delta})$, ETH followed by $1-\mathrm{MCP}(\mathrm{ETH}+1-\mathrm{MCP}, \ldots \bullet \ldots)$, and 1-MCP followed by ETH (1-MCP + ETH, ... $\boldsymbol{\Delta} \ldots)$.

The relative expression of the $C m-A A T$ genes showed similar patterns in peel and flesh tissues of Caihong7 and Tianbao fruit, and was significantly higher in the former cultivar than in the latter $(P<0.05)$, except for $C m$-AAT3 (Fig. 7; Supplemental Fig. 4). A massive accumulation of $A A T$ transcripts was observed to occur concomitantly with the ETH production rate. A significant reduction in the $A A T$ transcript accumulation was observed in ETH-treated and control 'Caihong7' fruit after day 6. The expression of $C m-A A T$ was significantly increased in ETH-treated fruit compared with the corresponding control $(P<0.05)$. Suppression of ETH action by 1-MCP significantly inhibited $A A T$ transcript accumulation, especially those of $C m-A A T 1, C m-A A T 2$, and $C m-A A T 4$; in comparison, $C m-A A T 3$ was not completely suppressed by 1-MCP.

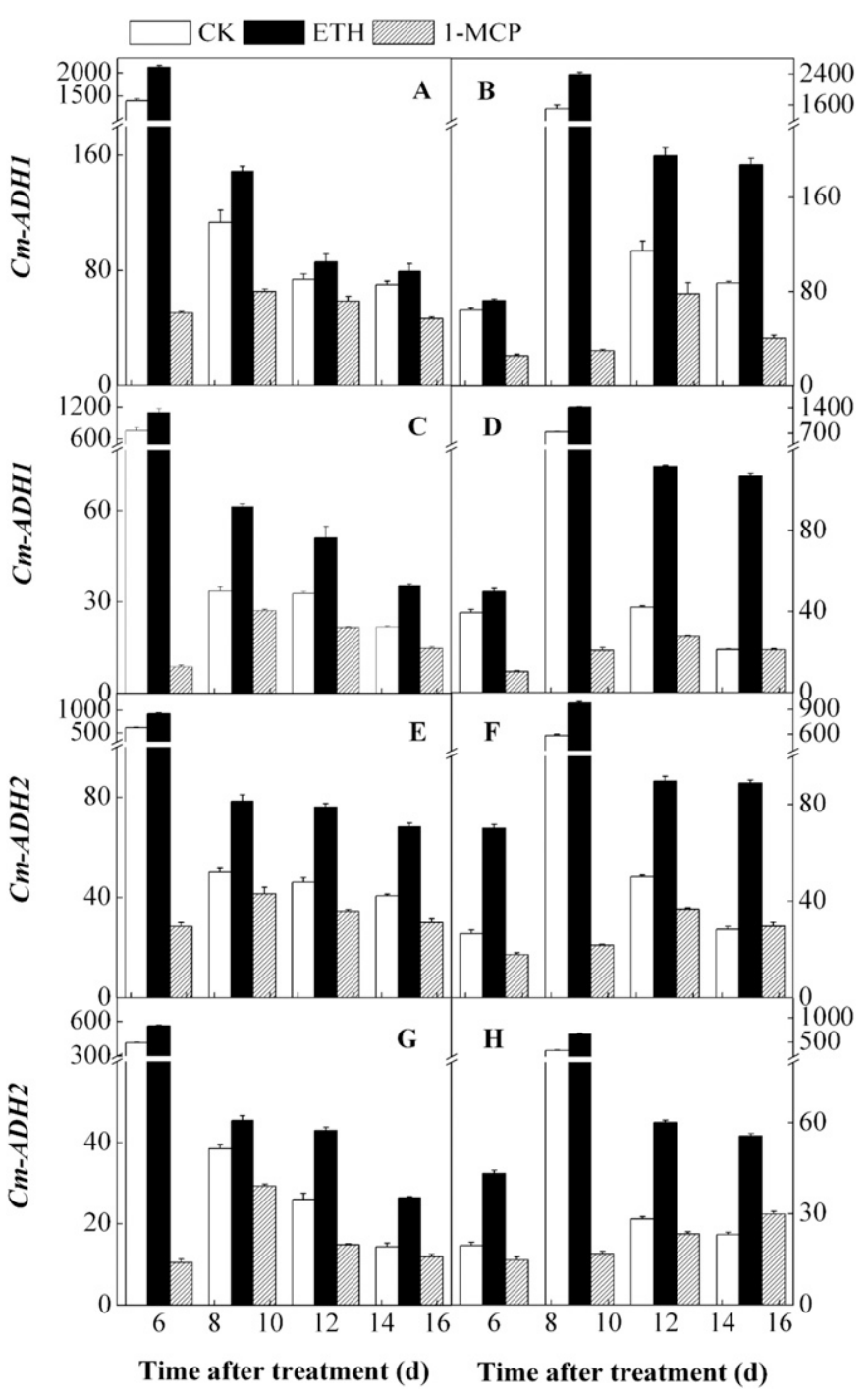

Fig. 6. Effects of ethylene (ETH) and 1-methylcyclopropene (1-MCP) on expression of (A-D) $C m-A D H 1$ and (E-H) $C m-A D H 2$ in peel (upper) and flesh (lower) tissues of 'Caihong7' (left) and 'Tianbao' (right) oriental sweet melon fruit during storage at room temperature $\left(23^{\circ} \mathrm{C}\right)$ for up to $15 \mathrm{~d}$. Values are means $\pm \operatorname{SE}(\mathrm{n}=3)$. Distilled water was the control $(\mathrm{CK})$.

\section{Discussion}

Flores (2008) investigated antisense melon fruit with inhibited autocatalytic ETH production and found that exposing it to ETH catalyzed the biosynthesis of endogenous ETH and promoted the respiratory climacteric. Our results were consistent with some parts of previous studies. Contrarily, ETH can advance the onset of the climacteric peak of ETH production in cantaloupe (Cucumis melo var. cantalupensis) (Pech et al., 2008), and the onset of the peak for the rate of ETH production was not changed by ETH treatment in Caihong 7 and Tianbao in our study, probably due to the differences in the plant species or cultivars and physiological behavior.

Aldehydes are known to serve as key aroma compounds in fruits, in which they impart a cucumber-like flavor (Kemp et al., 1974); they are also known to be higher in concentration in immature melon fruit (Beaulieu and Grimm, 2001). In the present study, Tianbao was found to exhibit more of a cucumberlike flavor, which was mainly due to the significantly higher 


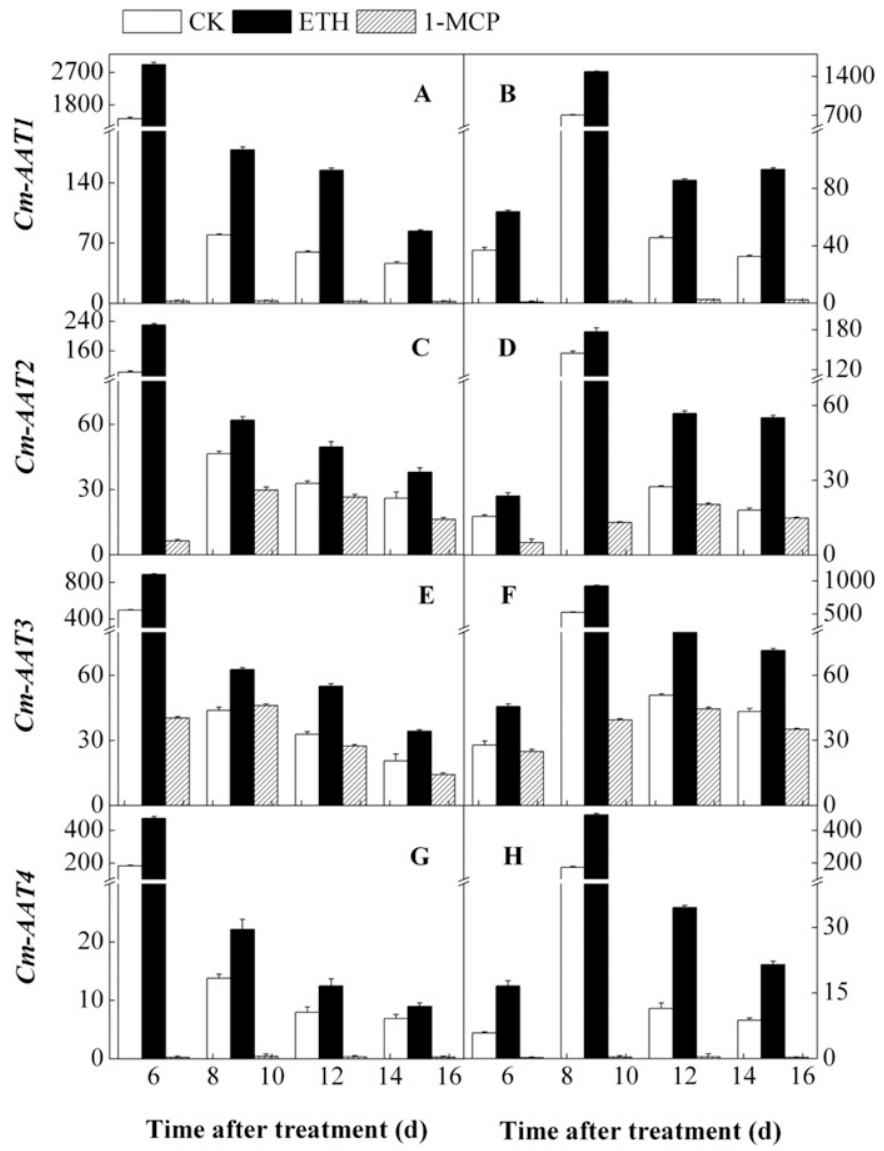

Fig. 7. Effects of ethylene (ETH) and 1-methylcyclopropene (1-MCP) on expression of $(\mathbf{A}, \mathbf{B}) C m-A A T 1,(\mathbf{C}, \mathbf{D}) C m-A A T 2,(\mathbf{E}, \mathbf{F}) C m-A A T 3$, and $(\mathbf{G}, \mathbf{H}) C m-A A T 4$ in flesh tissue of 'Caihong7' (left) and 'Tianbao' (right) oriental sweet melon fruit during storage at room temperature $\left(23^{\circ} \mathrm{C}\right)$ for up to $15 \mathrm{~d}$. Values are means $\pm S E(n=3)$. Distilled water was the control $(C K)$.

contents of $\mathrm{C}_{6}$ aldehydes and alcohols than Caihong7, this appeared to be a key factor affecting the flavors of both cultivars. Esters are important contributors to the aroma of oriental sweet melon (Li et al., 2011) and similar to the results from a previous study (Li et al., 2014), our data confirmed that the amount of esters produced by oriental sweet melon fruit increased dramatically during storage; in contrast, the amount of aldehydes formed under the same conditions was lower. The ANOVA data demonstrated that the levels of esters produced from $\mathrm{C}_{1}$ and $\mathrm{C}_{2}$ alcohols as well as $\mathrm{C}_{6}$ and $\mathrm{C}_{9}$ acyl CoAs increased the most during storage in both cultivars. Coincidentally, most of these compounds confer aroma properties to melon fruit (Liu et al., 2009; Obando-Ulloa et al., 2009; Shieh and Chang, 2001). Moreover, significantly higher levels of these esters were detected in the highly aromatic 'Caihong7' relative to the less aromatic 'Tianbao'. Esters behavior may also play a role in discriminating 'Caihong7' from 'Tianbao' using volatiles.

The variations in the total level of straight-chain esters coinciding with the ETH production rate in our research suggested that the total ester production was regulated by ETH in oriental sweet melon. The levels of hexyl acetate were significantly increased by ETH but suppressed by 1-MCP in the present study, indicating that levels of hexyl esters derived from hexanal followed an ETH-dependent pattern. A certain contribution of ethyl acetate is necessary for the aroma of oriental sweet melon (Liu et al., 2009). Several previous studies have shown no significant differences in the levels of ethyl acetate during ripening in fruit of related climacteric melons with introgression of an oriental one (Fernández-Trujillo et al., 2013), and this compound has also been associated with senescence (Obando-Ulloa et al., 2009). However, ethyl acetate was emitted to a greater extent in ETH-treated 'Caihong7' fruit than in 'Tianbao' fruit in the present study. It seemed that the accumulation of this compound was partly dependent on the plant cultivar and the physiological behavior of the fruit, and further studies are required to confirm this. On the other side, these results suggested that there was a concentration-dependent response of aroma volatile production to ETH by comparing the individual melon results to the combined fruit results. Part of the response to ETH may have been due to better coordination of ripening compared with control and 1-MCP fruit, leading to higher apparent levels of the features measured because the changes were occurring at closer to the same time in all melons in the ETH treatment. This could be verified in our future work. The majority of the butyrate levels showed an increasing tendency in the ETH-/1-MCP-treated and untreated fruit of 'Caihong7' and 'Tianbao' throughout the storage period, which showed that butyrate levels were primarily affected by senescence instead of ETH.

A previous study showed that treatment of immature apple (Malus $\times$ domestica) fruit with ETH increased their FA concentration (Song and Bangerth, 2003), and similar findings were observed in the present work. The increase in FA levels after ETH treatment suggested that ester formation and upstream steps in the ester biosynthetic pathway were dependent on ETH. Similar patterns of reductions in LA, LeA, and OA during storage could explain the decrease in the total levels of aldehydes. However, the decline in $\mathrm{C}_{6}$ aldehydes from the ETH-treated 'Tianbao' fruit was not likely to have been caused by changes in FA precursors during fruit ripening, although previous studies have shown that modification of FA profiles can cause changes in the levels of volatile compounds (Canoles and Beaudry, 2006). Such a result may be due to the higher activities of ADH or AAT in fruit treated with ETH, which can catalyze the conversion of more aldehydes to downstream products, although increased levels of LOX and HPL activity have been simultaneously observed in ETH-treated fruit.

The biosynthesis of straight-chain esters largely depends on an adequate supply of lipid-derived precursors (Schwab et al., 2008). As previously stated, the positive effect of ETH on LOX activity suggested that this enzyme was dependent on ETH, which was consistent with the results of Dandekar et al. (2004). No significant differences in HPL activity in flesh tissues were observed in both cultivars, which may demonstrate the relatively weak regulatory role of ETH on this enzyme, and further studies are needed to prove this. Contrary to the higher activity observed in peel than in flesh of both cultivars, other researchers have observed different tissue-specific diversity in the HPL activity found in peel and flesh from peach [Prunus persica (Ortiz et al., 2010)]. The activity of this enzyme may thus depend on the species. Zhang et al. (2010) showed that decreases in PpHPL1 expression may contribute to the reduction of $\mathrm{C}_{6}$ aldehydes. In contrast, the present study showed higher concentrations of $\mathrm{C}_{6}$ aldehydes in ETH-treated fruit of both cultivars, as well as lower levels of HPL activity at the initial stage of experiment. As such, further tests on HPL activity should be conducted at the transcriptional level in 
oriental sweet melon during postharvest ripening. Moreover, with the exception of LOX, the $\mathrm{pH}$ of reaction solution for enzymes HPL, ADH, and AAT was not optimized for oriental sweet melon fruit tissue; the effect of optimal $\mathrm{pH}$ could have species dependence for the same enzyme, and further studies should be needed to verify these speculations (Lester et al., 2004).

Rapid increases in the emissions of hexanoate, hexenyl, and hexyl esters may have arisen from the extensive hexanal and hexenal availability in both ETH-treated cultivars. According to the ANOVA data, the significantly lower level of hexanal in both ETH-treated cultivars after treatment indicated that hexanal was diverted to the production of hexanoate and may be reduced to hexan-1-ol, a direct precursor of hexyl esters, by the specific action of ADH. Therefore, the increased production of hexyl esters may have resulted from the increased ADH activity (Ortiz et al., 2010).

Decreased levels of AAT activity were followed by a remarkable increase in emitted ETH, as determined from the total emission of straight-chain esters. This result was in agreement with that of El-Sharkawy et al. (2005) who concluded that AAT was regulated by ETH. AAT expression has also been reported to be dependent on ETH in apple (Defilippi et al., 2005). The availability of alcohols was believed to be a bottleneck for ester production. Inhibition of ADH provided less alcohol substrates for ester biosynthesis and decreased AAT; thus, the aldehyde compounds accumulated in 1-MCP-treated fruit. In general, our results strongly suggested the relevance of the substrate supply for the biosynthesis of volatile compounds. This result was in accordance with that of a previous report (Lara et al., 2003, 2007), in which an adequate supply of precursors was observed to be a key factor influencing aroma volatile compound production when sufficient AAT activity was present. Taken together, these data suggested that significant reductions in ester compounds observed under ETH suppression conditions could also be caused by reductions in AAT activity levels and not just by limiting the availability of the precursors.

The onset of $C m-A D H$ and $C m-A A T$ expression in peel and flesh, which was responsible for aroma biosynthesis, coincided with the accumulation of ETH production. $\mathrm{Cm}-\mathrm{ADH} \mathrm{H}$ and $\mathrm{Cm}$ $A D H 2$ followed the same pattern in peel of both ETH-treated and control fruit, but peaked on day 6 in 'Caihong7' and day 9 in 'Tianbao', respectively. This appeared to be a cultivardependent response that corresponded with the peak of ETH production rate. The expression of $\mathrm{Cm}-\mathrm{ADH} 1$ and $\mathrm{Cm}-\mathrm{ADH} 2$ genes was upregulated by ETH and reduced by 1-MCP, thereby indicating positive regulation by ETH. This result was consistent with that found in a previous study on melon (Manríquez et al., 2006), although it was contradictory to the results from another similar study in apple (Defilippi et al., 2005), and this was likely dependent on the plant species.

The diversity of volatile esters has been demonstrated to arise from the multiplicity of genes encoding AAT enzymes with differing specific substrate selectivity (D'Auria, 2006; Lucchetta et al., 2007). The AAT1 locus was found to be critical for the biosynthesis of esters, and contributes to a "ripe apple" flavor (Souleyre et al., 2014). Galaz et al. (2013) studied CmAAT proteins in melon, and found that CmAAT1 preferentially leads to the synthesis of hexyl acetate, $C m A A T 3$ to benzyl acetate, and $C m A A T 4$ to cinnamyl acetate, whereas $C m A A T 2$ is inactive. Lee et al. (2014) studied $A A T$ genes in oriental sweet melons but was related with the shikimate pathway in the flesh, stalk, and peel. Moreover, the expression of $C m-A A T 1-4$ was confirmed to be positively regulated by ETH in kiwifruit [Actinidia sp. (Günther et al., 2015)]. However, in our study, the inhibition of $C m-A A T 3$ expression in 1-MCP-treated fruit was relatively weak compared with that of $C m-A A T 1, C m$ $A A T 2$, and $C m-A A T 4$. This result implied that the regulation of $C m-A A T 3$ by ETH was relatively weak, and $C m-A A T 1$ and $C m$ $A A T 4$ may be involved in important functions in the aromatic volatile compound formation regulated by ETH. The activity of AAT in 1-MCP-treated fruit was significantly reduced compared with that in control fruit. However, the degree of suppression of enzymatic activity was less than that of the mRNA levels, suggesting that there are likely as yet unidentified $A A T$ genes within the oriental sweet melon genome, which was in agreement with the work of Shan et al. (2012). Changes in AAT activity in all treatments of 'Caihong7' and 'Tianbao' oriental sweet melon were not consistent with the pattern observed in $A A T$ expression. This finding implied that AAT activity was partially depended on ETH (Flores et al., 2002). In contrast with the $A A T$ translation levels observed, ETH suppression and enhancement did not affect the translation levels of $A D H$. This tendency suggested that the dramatic changes in $A D H$ translation were not completely regulated by ETH; other plant hormones or metabolites may be involved in this mechanism. As the $L O X$ gene is found in many species, more research is required to describe the presence and function of the $L O X$ gene in oriental sweet melons.

\section{Literature Cited}

Allwood, J.W., W. Cheung, Y. Xu, R. Mumm, R.C.H. De Vos, C. Deborde, B. Biais, M. Maucourt, Y. Berger, A.A. Schaffer, D. Rolin, A. Moing, R.D. Hall, and R. Goodacre. 2014. Metabolomics in melon: A new opportunity for aroma analysis. Phytochemistry 99:61-72.

Aubert, C. and N. Bourger. 2004. Investigation of volatiles in Charentais cantaloupe melons (Cucumis melo var. cantalupensis). Characterization of aroma constituents in some cultivars. J. Agr. Food Chem. 52:4522-4528.

Bai, X.H., L.H. Teng, D.Q. Lü, and H.Y. Qi. 2014. Co-treatment of $\mathrm{EFF}$ and 1-MCP for enhancing the shelf-life and aroma volatile compounds of oriental sweet melons (Cucumis melo var. makuwa Makino). J. Integr. Agr. 13:217-227.

Baldwin, E.A., J.W. Scott, C.K. Shewmaker, and W. Schuch. 2000. Flavor trivia and tomato aroma: Biochemistry and possible mechanisms for control of important aroma components. HortScience 35:1013-1022.

Beaulieu, J.C. 2005. Within-season volatile and quality differences in stored fresh-cut cantaloupe cultivars. J. Agr. Food Chem. 53:86798687.

Beaulieu, J.C. and C. Grimm. 2001. Identification of volatile compounds in cantaloupe at various developmental stages using solid phase microextraction. J. Agr. Food Chem. 49:1345-1352.

Bernillon, S., B. Biais, C. Deborde, M. Maucourt, C. Cabasson, Y. Gibon, T.H. Hansen, S. Husted, R.C. de Vos, R. Mumm, H. Jonker, J. Ward, S.J. Miller, J.M. Baker, J. Burger, Y. Tadmor, M.H. Beale, J.K. Schjoerring, A.A. Schaffer, D. Rolin, R.D. Hall, and A. Moing. 2013. Metabolomic and elemental profiling of melon fruit quality as affected by genotype and environment. Metabolomics 9:57-77.

Bradford, M.M. 1976. A rapid and sensitive method for the quantitation of microgram quantities of protein utilizing the principle of protein dye binding. Anal. Biochem. 72:248-254.

Burger, Y., U. Sa'ar, H.S. Paris, E. Lewinsohn, N. Katzir, Y. Tadmor, and A.A. Schaffer. 2006. Genetic variability for valuable fruit quality traits in Cucumis melo. Isr. J. Plant Sci. 54:233-242. 
Canoles, M.A. and R.M. Beaudry. 2006. Deficiency of linolenic acid in Lefad7 mutant tomato changes the volatile profile and sensory perception of disrupted leaf and fruit tissue. J. Amer. Soc. Hort. Sci. 131:284-289.

Chaparro-Torres, L.A., M.C. Bueso, and J.P. Fernández-Trujillo. 2016. Aroma volatiles obtained at harvest by HS-SPME/GC-MS and INDEX/MS-E-nose fingerprint discriminate climacteric behaviour in melon fruit. J. Sci. Food Agr. 96:2352-2365.

Chen, K.S., C.J. Xu, W.P. Xu, M. Wu, and S.L. Zhang. 2003. Improved method for detecting lipoxygenase activity from kiwi fruit and peach fruit. J. Fruit Sci. 6:436-438.

D'Auria, J.C. 2006. Acyltransferases in plants: A good time to be BAHD. Curr. Opin. Plant Biol. 9:331-340.

Dandekar, A.M., G. Teo, B. Defilippi, S.L. Uratsu, A.J. Passey, and A.A. Kader. 2004. Effect of down-regulation of ethylene biosynthesis on fruit flavor complex in apple fruit. Transgenic Res. 13:373-384.

Defilippi, B.G., A.A. Kader, and A.M. Dandekar. 2005. Apple aroma: Alcohol acyltransferase, a rate limiting step for ester biosynthesis, is regulated by ethylene. Plant Sci. 168:1199-1210.

Dos-Santos, N., M.C. Bueso, and J.P. Fernández-Trujillo. 2013. Aroma volatiles as biomarkers of textural differences at harvest in non-climacteric near-isogenic lines of melon. Food Res. Intl. 54:1801-1812.

El-Sharkawy, I., D. Manríquez, F.B. Flores, F. Regad, M. Bouzayen, A. Latché, and J.C. Pech. 2005. Functional characterization of a melon alcohol acyl-transferase gene family involved in the biosynthesis of ester volatiles. Identification of the crucial role of a threonine residue for enzyme activity. Plant Mol. Biol. 59:345-362.

Fellman, J.K., T.W. Miller, D.S. Mattison, and J.P. Matheis. 2000. Factors that influence biosynthesis of volatile flavor compounds in apple fruits. HortScience 35:1026-1033.

Fernández-Trujillo, J.P., N. Dos-Santos, R. Martínez-Alcaraz, and I. Le Bleis. 2013. Non-destructive assessment of aroma volatiles from a climacteric near-isogenic line of melon obtained by headspace stirbar sorptive extraction. Foods 2:401-414.

Flores, F. 2008. Influence of fruit development stage on the physiological response to ethylene in cantaloupe Charentais melon. Food Sci. Technol. Intl. 14:87-94.

Flores, F., F. El-Yahyaoui, G. de Billerbeck, F. Romojaro, A. Latché, M. Bouzayen, J.C. Pech, and C. Ambid. 2002. Role of ethylene in the biosynthetic pathway of aliphatic ester aroma volatiles in Charentais cantaloupe melons. J. Expt. Bot. 53:201-206.

Galaz, S., L. Morales-Quintana, M.A. Moya-León, and R. Herrera. 2013. Structural analysis of the alcohol acyltransferase protein family from Cucumis melo shows that enzyme activity depends on an essential solvent channel. FEBS J. 280:1344-1357.

Giovannoni, J.J. 2004. Genetic regulation of fruit development and ripening. Plant Cell 16:170-180.

Günther, C.S., K.B. Marsh, R.A. Winz, R.F. Harker, M.W. Wohlers, A. White, and M.R. Goddard. 2015. The impact of cold storage and ethylene on volatile ester production and aroma perception in 'Hort16A' kiwifruit. Food Chem. 169:5-12.

Kemp, T.R., D.E. Knavel, L.P. Stoltz, and R.E. Lundin. 1974. 3,6Nonadien-1-ol from Citrullus vulgaris and Cucumis melo. Phytochemistry 13:1167-1170.

Khanom, M.M. and Y. Ueda. 2008. Bioconversion of aliphatic and aromatic alcohols to their corresponding esters in melons (Cucumis melo L. cv. Prince melon and cv. Earl's favorite melon). Postharvest Biol. Technol. 50:18-24.

Klee, H.J. and J.J. Giovannoni. 2011. Genetics and control of tomato fruit ripening and quality attributes. Annu. Rev. Genet. 45:41-59.

Lara, I., G. Echeverría, J. Graell, and M.L. López. 2007. Volatile emission after controlled atmosphere storage of Mondial Gala apples (Malus domestica): Relationship to some involved enzyme activities. J. Agr. Food Chem. 55:6087-6095.

Lara, I., R.M. Miró, T. Fuentes, G. Sayez, J. Graell, and M.L. López. 2003. Biosynthesis of volatile aroma compounds in pear fruit stored under long-term controlled-atmosphere conditions. Postharvest Biol. Technol. 29:29-39.

Lee, J., M.K. Kim, S.H. Hwang, J. Kim, J.M. Ahn, S.R. Min, S.U. Park, S.S. Lim, and H.R. Kim. 2014. Phenotypic profiling and gene expression analyses for aromatic and volatile compounds in chamoes (Cucumis melo). Mol. Biol. Rpt. 41:3487-3497.

Lester, G.E., H.D. Mark, R.D. Meyer, and K.D. Munro. 2004. Preextraction preparation (fresh, frozen, freeze-dried, or acetone powdered) and long-term storage of fruit and vegetable tissues: Effects on antioxidant enzyme activity. J. Agr. Food Chem. 52:2167-2173.

Li, G.P., H.J. Jia, J.H. Li, Q. Wang, M.J. Zhang, and Y.W. Teng. 2014. Emission of volatile esters and transcription of ethylene- and aromarelated genes during ripening of 'Pingxiangli' pear fruit (Pyrus ussuriensis Maxim). Sci. Hort. 170:17-23.

Li, Y., H.Y. Qi, Y.Z. Jin, X.B. Tian, L.L. Sui, and Y. Qiu. 2016. Role of ethylene in biosynthetic pathway of related-aroma volatiles derived from amino acids in oriental sweet melons (Cucumis melo var. makuwa Makino). Sci. Hort. 201:24-35.

Li, Y., H.Y. Qi, Y.F. Liu, X.C. Guan, and Y.F. Liu. 2011. Effects of ethephon and 1-methylcyclopropene on fruit ripening and the biosynthesis of volatiles in oriental sweet melon (Cucumis melo var. makuwa Makino). J. Hort. Sci. Biotechnol. 86:517-526.

Liu, W.W., H.Y. Qi, B.H. Xu, Y. Li, X.B. Tian, Y.Y. Jiang, X.F. Xu, and D.Q. Lv. 2012. Ethanol treatment inhibits internal ethylene concentrations and enhances ethyl ester production during storage of oriental sweet melons (Cucumis melo var. makuwa Makino). Postharvest Biol. Technol. 67:75-83.

Liu, Y., H.Y. Qi, B. Wang, D.J. Zhang, and N.N. Yi. 2009. Correlation between sensory analysis and major flavor compounds in melon of five groups. Acta Agr. Boreali-Occidentalis Sinica 18:355-358.

Longhurst, T.J., J.F. Tung, and C.J. Brady. 1990. Developmental regulation of the expression of alcohol dehydrogenase in ripening tomato fruit. J. Food Biochem. 14:421-423.

Lucchetta, L., D. Manriquez, I. El-Sharkawy, F.B. Flores, P. Sanchez-Bel, M. Zouine, C. Ginies, M. Bouzayen, C. Rombaldi, J.C. Pech, and A. Latché. 2007. Biochemical and catalytic properties of three recombinant alcohol acyltransferases of melon. Sulfur-containing ester formation, regulatory role of $\mathrm{CoA}-\mathrm{SH}$ in activity, and sequence elements conferring substrate preference. J. Agr. Food Chem. 55:5213-5220.

Manríquez, D., I. El-Sharkawy, F.B. Flores, F. El Yahyaoui, F. Regad, M. Bouzayen, A. Latche, and J.C. Pech. 2006. Two highly divergent alcohol dehydrogenases of melon exhibit fruit ripening-specific expression and distinct biochemical characteristics. Plant Mol. Biol. 61:675-685.

Nie, L.C., J.S. Sun, and B. Di. 2005. Changes in amino acid and fatty acid contents as well as activity of some related enzymes in apple fruit during aroma production (in Chinese). J. Plant Physiol. Mol. Biol. 31:663-667.

Obando-Ulloa, J.M., E. Moreno, J. Garcia-Mas, B. Nicolai, J. Lammertync, A.J. Monforte, and J.P. Fernandez-Trujillo. 2008. Climacteric or nonclimacteric behavior in melon fruit: 1 . Aroma volatiles. Postharvest Biol. Technol. 49:27-37.

Obando-Ulloa, J.M., B. Nicolai, J. Lammertyn, M.C. Bueso, A.J. Monforte, and J.P. Fernández-Trujillo. 2009. Aroma volatiles associated with the senescence of climacteric or non-climacteric melon fruit. Postharvest Biol. Technol. 52:146-155.

Ortiz, A., J. Graell, M.L. López, G. Echeverría, and I. Lara. 2010. Volatile ester-synthesising capacity in 'Tardibelle' peach fruit in response to controlled atmosphere and 1-MCP treatment. Food Chem. 123:698-704.

Pech, J.C., M. Bouzayen, and A. Latché. 2008. Climacteric fruit ripening: Ethylene-dependent and independent regulation of ripening pathways in melon fruit. Plant Sci. 175:114-120.

Périn, C., M. Gómez-Jiménez, L. Hagen, C. Dogimont, J.C. Pech, A. Latché, M. Pitrat, and J.M. Lelièvre. 2002. Molecular and genetic characterization of a non-climacteric phenotype in melon reveals two 
loci conferring altered ethylene response in fruit. Plant Physiol. 129:300-309.

Portnoy, V., Y. Benyamini, E. Bar, R. Harel-Beja, S. Gepstein, J.J. Giovannoni, A.A. Schaffer, J. Burger, Y. Tadmor, E. Lewinsohn, and N. Katzir. 2008. The molecular and biochemical basis for varietal variation in sesquiterpene content in melon (Cucumis melo L.) rinds. Plant Mol. Biol. 66:647-661.

Qi, H.Y., Y. Li, X.C. Guan, J.R. Li, L.Y. Qiu, and J. Hao. 2011. Analysis of ripening characteristics, aroma components and aroma-related enzymes in oriental sweet melons (Cucumis melo var. makuwa Makino) (in Chinese). Scientia Agricultura Sinica 44:771-780.

Salas, J. and J. Sanchez. 1999. Hydroperoxide lyase from olive (Olea europaea) fruits. Plant Sci. 143:19-26.

Schwab, W., R. Davidovich-Rikanati, and E. Lewinsohn. 2008. Biosynthesis of plant-derived flavor compounds. Plant J. 54:712-732.

Shalit, M., N. Katzir, Y. Tadmor, O. Larkov, Y. Burger, F. Shalekhet, E. Lastochkin, U. Ravid, O. Amar, M. Edelstein, Z. Karchi, and E. Lewinsohn. 2001. Acetyl CoA: Alcohol acetyl transferase activity and aroma formation in ripening melon fruits. J. Agr. Food Chem. 49:794-799. Shan, W.Y., C. Zhao, J.G. Fan, H.Z. Cong, S.C. Liang, and X.Y. Yu. 2012. Antisense suppression of alcohol acetyltransferase gene in ripening melon fruit alters volatile composition. Sci. Hort. 139:96-101.

Shieh, C.J. and S.W. Chang. 2001. Optimized synthesis of lipasecatalyzed hexyl acetate in n-hexane by response surface methodology. J. Agr. Food Chem. 49:1203-1207.
Song, J. and F. Bangerth. 2003. Fatty acids as precursors for aroma volatile biosynthesis in pre-climacteric and climacteric apple fruit. Postharvest Biol. Technol. 30:113-121.

Souleyre, E.J.F., D. Chagne, X.Y. Chen, R. Tomes, R.M. Turner, M.Y. Wans, R. Maddumage, M.B. Hunt, R.A. Winz, C. Wiedows, C. Hamiaux, S.E. Gardiner, D.D. Rowan, and R.G. Atkinson. 2014. The AAT1 locus is critical for the biosynthesis of esters contributing to 'ripe apple' flavour in 'Royal Gala' and 'Granny Smith' apples. Plant J. 78:903-915.

Tian, X.B., H.Y. Qi, Y. Li, Y.Z. Jin, W.W. Liu, and X.F. Xu. 2012. Effects of different rootstocks on ripening quality, activities and gene expression of aroma-related enzymes in grafting oriental sweet melon (Cucumis melo var. makuwa Makino) (in Chinese). Scientia Agricultura Sinica 9:1766-1774.

Wyllie, S.G. and D.N. Leach. 1992. Sulfur-containing compounds in the aroma volatiles of melons (Cucumis melo). J. Agr. Food Chem. 40:253-256.

Zhang, B., J.Y. Shen, W.W. Wei, W.P. Xi, C.J. Xu, I. Ferguson, and K.S. Chen. 2010. Expression of genes associated with aroma formation derived from the fatty acid pathway during peach fruit ripening. J. Agr. Food Chem. 58:6157-6165.

Zhang, B., X.R. Yin, X. Li, S.L. Yang, I. Ferguson, and K.S. Chen. 2009. Lipoxygenase gene expression in ripening kiwifruit in relation to ethylene and aroma production. J. Agr. Food Chem. 57:28752881. 


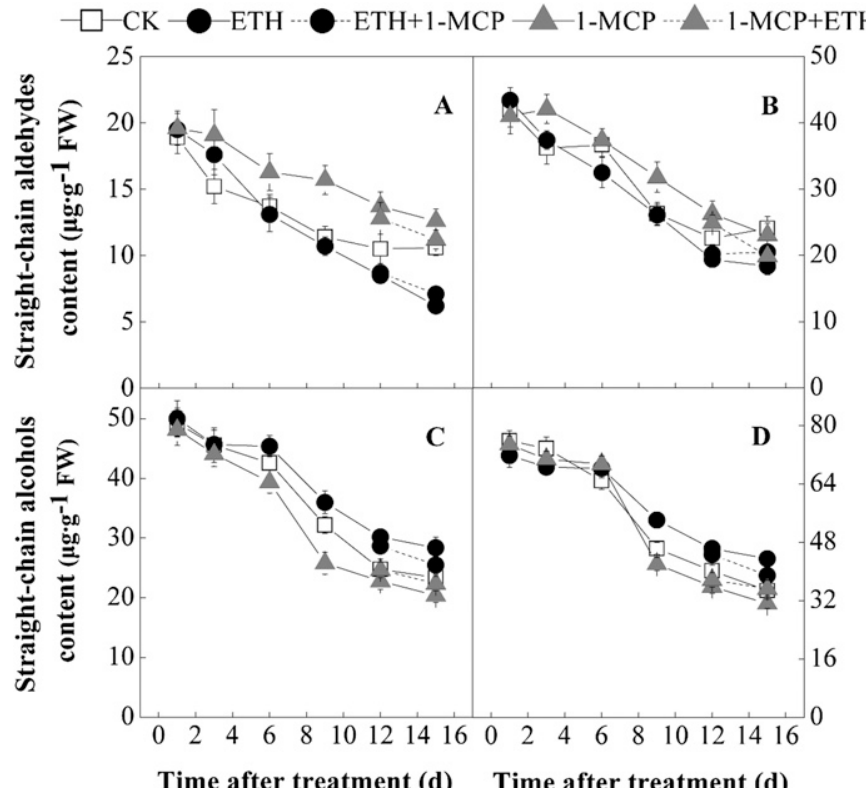

Supplemental Fig. 1. Effects of ethylene (ETH) and 1-methylcyclopropene (1-MCP) on content of $(\mathbf{A}, \mathbf{B})$ straight-chain aldehydes and $(\mathbf{C}, \mathbf{D})$ alcohols in peel tissues of 'Caihong7' (left) and 'Tianbao' (right) oriental sweet melon fruit during storage at room temperature $\left(23^{\circ} \mathrm{C}\right)$ for up to $15 \mathrm{~d}$. Values are means $\pm \mathrm{SE}(\mathrm{n}=3)$. Distilled water was the control $[\mathrm{CK}(\square)], 10 \mathrm{mg} \cdot \mathrm{L}^{-1}$ ETH treatment $(\bullet), 1 \mathrm{mg} \cdot \mathrm{L}^{-1} 1-\mathrm{MCP}(\boldsymbol{\Delta}), \mathrm{ETH}$ followed by 1-MCP $(\mathrm{ETH}+$ $1-\mathrm{MCP}, \ldots \bullet \ldots)$, and 1 -MCP followed by ETH $(1-\mathrm{MCP}+\mathrm{ETH}, \ldots \boldsymbol{\Lambda} \ldots)$.

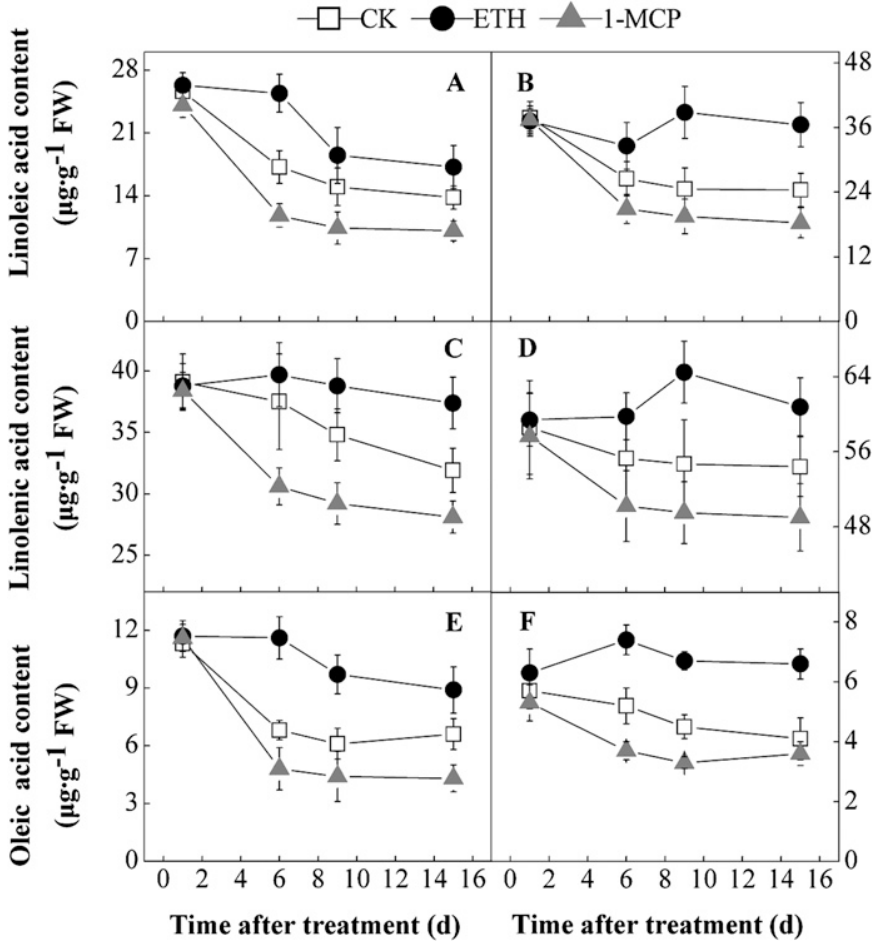

Supplemental Fig. 2. Effects of ethylene (ETH) and 1-methylcyclopropene $(1-\mathrm{MCP})$ on $(\mathbf{A}, \mathbf{B})$ linoleic acid, $(\mathbf{C}, \mathbf{D})$ linolenic acid, and $(\mathbf{E}, \mathbf{F})$ oleic acid in peel tissue of 'Caihong7' (left) and 'Tianbao' (right) oriental sweet melon fruit during storage at room temperature $\left(23^{\circ} \mathrm{C}\right)$ for up to $15 \mathrm{~d}$. Values are means $\pm \operatorname{SE}(\mathrm{n}=3)$. Distilled water was the control $(\mathrm{CK})$. 


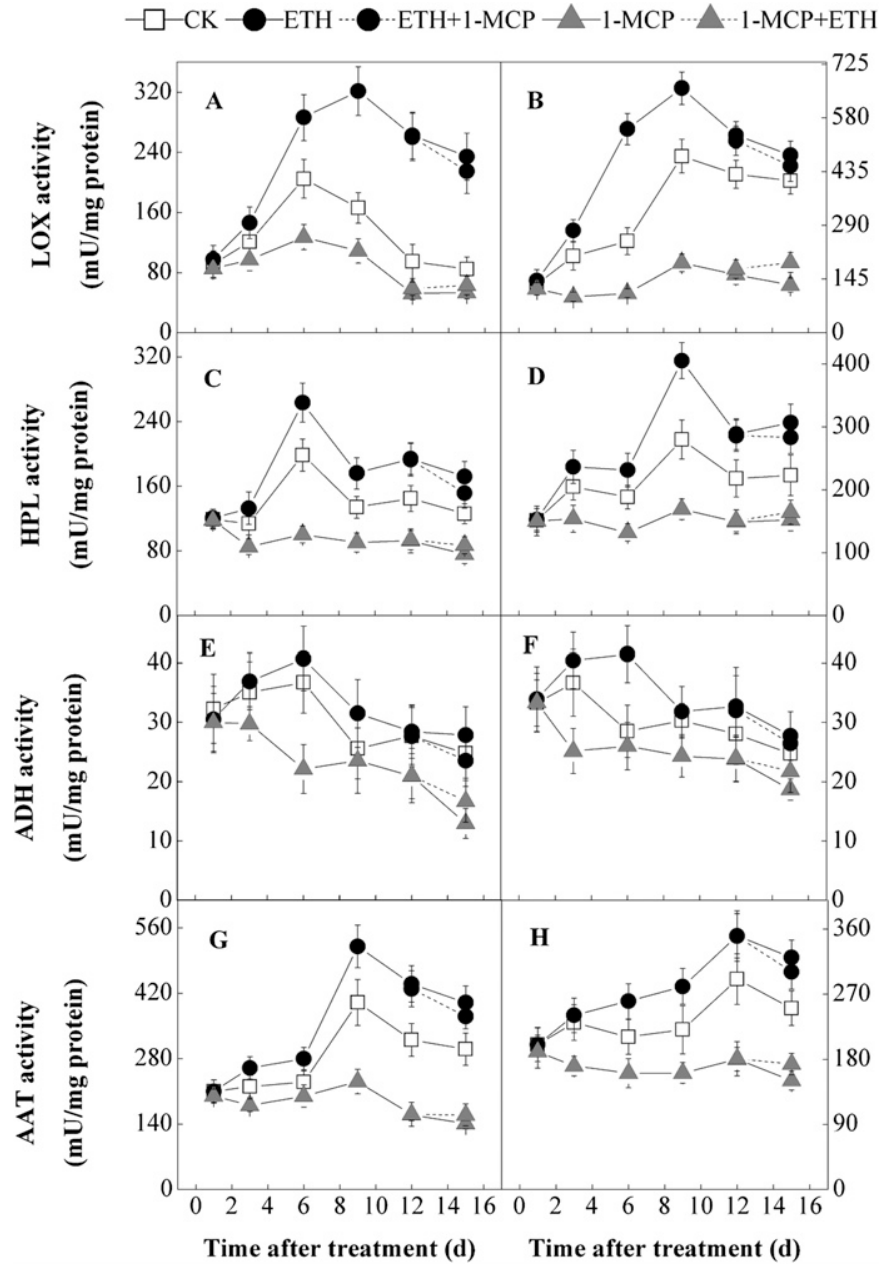

Supplemental Fig. 3. Effects of ethylene (ETH) and 1-methylcyclopropene (1-MCP) on activities of (A, B) lipoxygenase, $(\mathbf{C}, \mathbf{D})$ hydroperoxide lyase, $(\mathbf{E}, \mathbf{F})$ alcohol dehydrogenase, and $(\mathbf{G}, \mathbf{H})$ alcohol acetyltransferase in peel tissue of 'Caihong7' (left) and 'Tianbao' (right) oriental sweet melon fruit during storage at room temperature $\left(23^{\circ} \mathrm{C}\right)$ for up to $15 \mathrm{~d}$. Values are means $\pm \mathrm{SE}(\mathrm{n}=$ $3)$. Distilled water was the control $[\mathrm{CK}(\square)], 10 \mathrm{mg} \cdot \mathrm{L}^{-1} \mathrm{ETH}$ treatment $(\bullet)$, $1 \mathrm{mg} \cdot \mathrm{L}^{-1} 1-\mathrm{MCP}(\boldsymbol{\Lambda})$, ETH followed by 1-MCP $(\mathrm{ETH}+1-\mathrm{MCP}, \ldots \bullet \ldots)$, and 1-MCP followed by ETH (1-MCP + ETH, ... $\boldsymbol{\Lambda} \ldots)$.

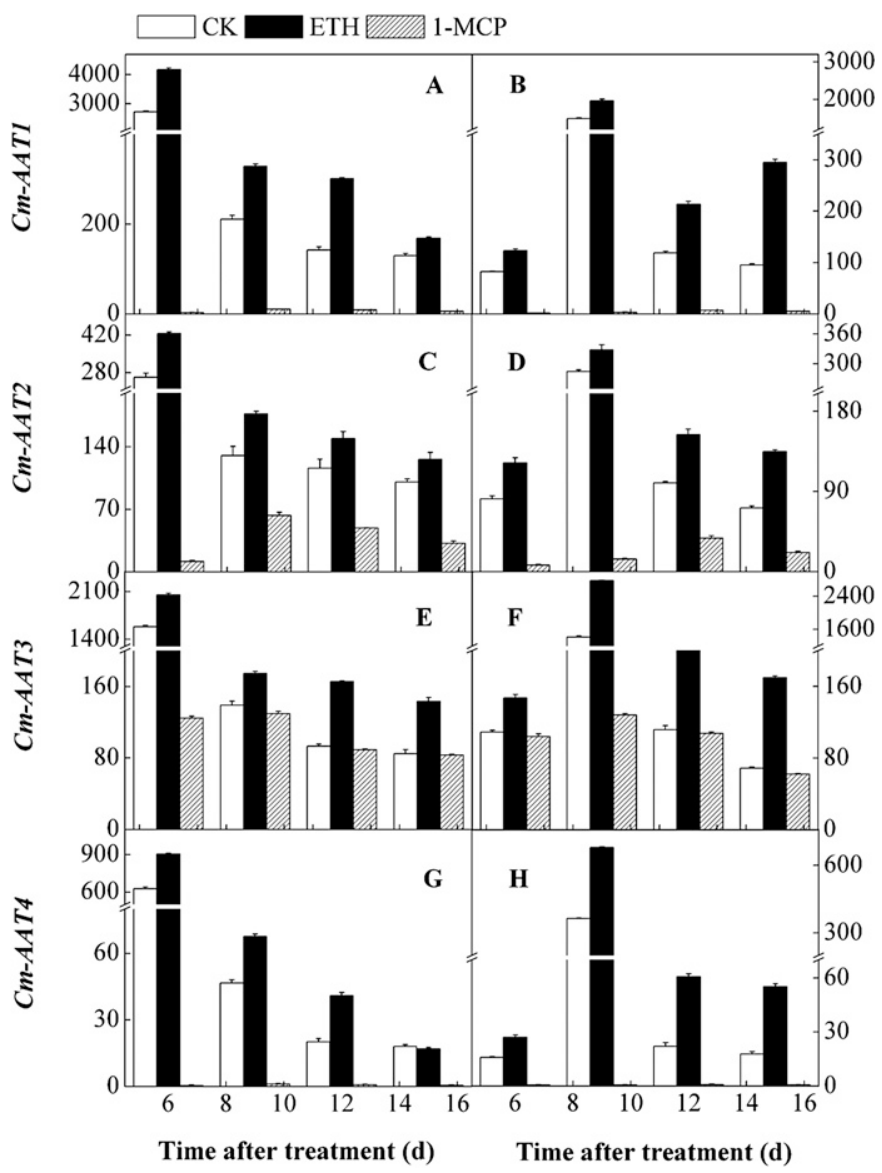

Supplemental Fig. 4. Effects of ethylene (ETH) and 1-methylcyclopropene (1-MCP) on expression of (A, B) Cm-AAT1, (C, D) Cm-AAT2, (E, F) Cm-AAT3, and $(\mathbf{G}, \mathbf{H}) C \mathrm{Cm}$-AAT4 in peel tissue of 'Caihong7' (left) and 'Tianbao' (right) oriental sweet melon fruit during storage at room temperature $\left(23^{\circ} \mathrm{C}\right)$ for up to $15 \mathrm{~d}$. Values are means $\pm \mathrm{SE}(\mathrm{n}=3)$. Distilled water was the control $(\mathrm{CK})$. 


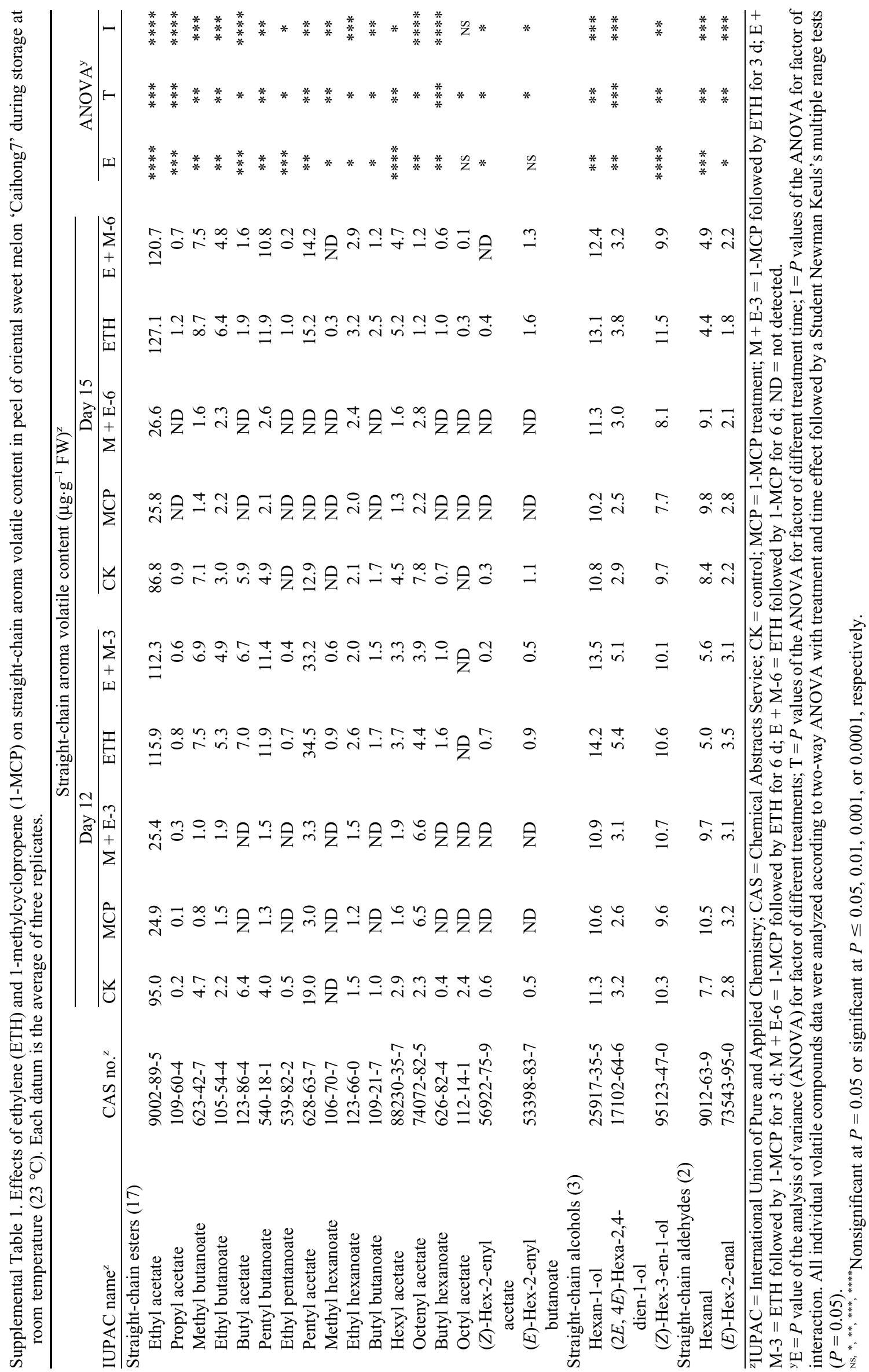




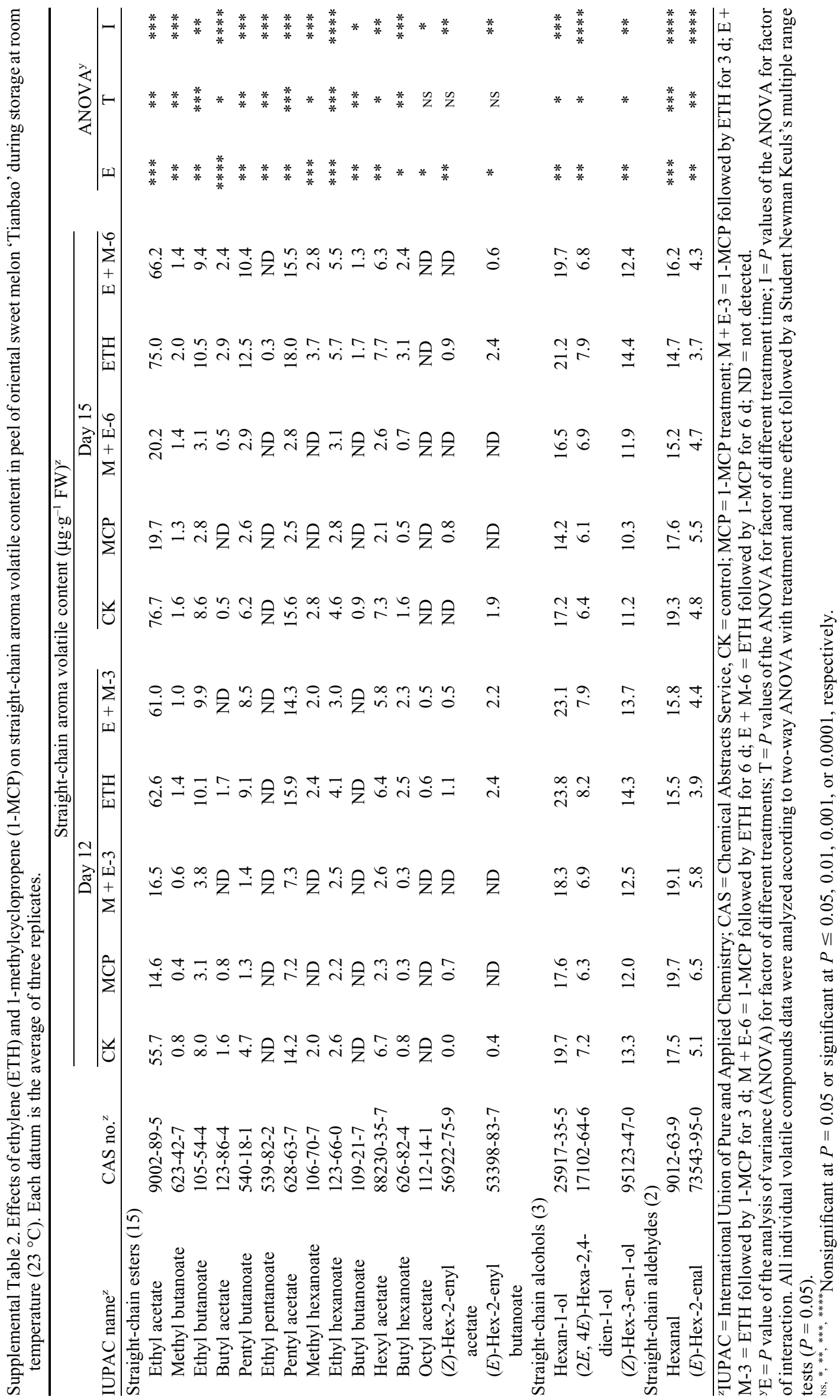

